\title{
RELACIONES INTERADMINISTRATIVAS Y DE CONFLICTO EN LA LEY BASICA DE REGIMEN LOCAL *
}

\author{
POR \\ LUCIANO PAREJO ALFONSO
}

\begin{abstract}
SUMARIO: I. AUTONOMIA LOCAL. COMPETENCIAS DE LOS ENTES LOCALES Y SISTEMA DE RELACIONES de ÉSTOS CON LAS OtRAS AdMINISTRACIONES TERRITORIALES: 1. Competencias propias (art. 7.2 LRBRL). 2. Competencias atribuidas (a medio de delegación: art. 7.3 LRBRL).-II. LA IMPUGNACIÓN JUDICIAL POR LAS ADMINISTRACIONES ESTATAL Y AUTONÓMICA DE LOS ACTOS Y ACUERDOS LOCALES: 1. Aspectos y cuestiones generales: 1.1 Carácter cerrado o abierto del sistema de impugnación y posibilidad o no de su desarrollo por la legislación autonómica de régimen local; 1.2 Construcción interna del régimen de impugnación de los actos y acuerdos locales sobre la base de la diferenciación de supuestos; 1.3 Inclusión de un régimen específico de legitimación activa; 1.4 Conflicto entre Administraciones y defensa de los derechos e intereses de los particulares afectados por el mismo; 1.5 Conexión entre régimen local y legislación contencioso-administrativa. 2. Los distintos supuestos legales: 2.1 El conflicto y la impugnación del artículo 65 LRBRL (arts. 214 y 215 ROFRJEL): 2.1.1 La excepción del agotamiento de la vía administrativa mediante la formulación del pertinente recurso; 2.1.2 La virtualidad del requerimiento en orden a la devolución al ente local de la potestad de anulación de sus actos o acuerdos; 2.1.3 El alcance de los requisitos formales impuestos al requerimiento; 2.1 .4 Los problemas que para el cómputo del plazo del requerimiento se deducen de la utilización de la facultad de pedir ampliación de la información sobre el acto o el acuerdo local; 2.1.5 La relación entre el requerimiento previo y la impugnación judicial; 2.1.6 La atención parcial del requerimiento; 2.1.7 El juego de la medida cautelar de suspensión en la fase judicial del conflicto. 2.2 El conflicto y la impugnación del artículo 66 LRBRL (art. 216 ROFRJEL): 2.2.1 ¿Es posible la formulación de requerimiento administrativo previo, con demora de la judicialización del conflicto?; 2.2 .2 Los requisitos formales de la impugnación: su alcance; 2.2 .3 La suspensión provisional o cautelar del acto o acuerdo objeto del conflicto. 2.3 El conflicto y la impugnación del artículo 67 LRBRL (art. 217 ROFRJEL): 2.3.1 La estructura del conflicto y sus elementos; 2.3.2 La fase administrativa del conflicto; aspectos más problemáticos; 2.3 .3 La fase judicial del conflicto.
\end{abstract}

- El presente texto corresponde a la conferencia pronunciada por el autor en las Jornadas sobre Administración Local y Justicia, organizadas por el Ayuntamiento de Barcelona y la Federación de Municipios de Cataluña, y celebradas en Barcelona del 20 al 23 de septiembre de 1988. 
I. AUTONOMIA LOCAL, COMPETENCIAS DE LOS ENTES LOCALES Y SISTEMA DE RELACIONES DE ESTOS CON LAS OTRAS ADMINISTRACIONES TERRITORIALES

La concepción de la autonomía local en el Derecho vigente, no como un conjunto o bloque acotado de asuntos que, al propio tiempo que circunscribe rigurosamente la acción legítima de los entes correspondientes, se entrega a los mismos para su entera administración bajo la propia responsabilidad (autónomamente), sino más bien como una cualidad y el consecuente estatuto (autoadministración) de las pertinentes colectividades institucionalizadas (a través de sus organizaciones corporativas representativas) conforme a los que se gestionan cualesquiera asuntos públicos que incumban a las mismas (en las que éstas tengan interés), con independencia del alcance de la intervención que en tales asuntos le atribuya la formalización jurídica de dicha incumbencia o interés (su traducción en competencias, habilitaciones-mandatos de actuacióni), hace que

a) Si bien la competencia asignada pueda tener $y$, de hecho, tenga con toda normalidad un contenido $y$ alcance variables en los diferentes asuntos;

b) El régimen de ejercicio o actuación de dicha competencia sea siempre único y el mismo (justamente porque tal actuación se realiza siempre por la misma organización autónoma).

Esta comprobación capital se cumple en la clasificación legal de las competencias legales, cuya tipología da lugar a los supuestos que -desde la perspectiva adoptada-cabe exponer así:

\section{Competencias propias (art. 7.2 LRBRL)}

En principio, la categoría se refiere al arquetipo mismo de la competencia local, en el que se da una coincidencia entre las dos concepciones expuestas de la autonomia local; arquetipo, que alude -por definición- a dos elementos: la índole del asunto (ha de tratarse de asuntos que se agotan en el interés local o en los de cualquier otro interés más amplio o superior, sea sólo secundario o accidental) y el alcance de la habilitación legal de actuación (ha de tratarse, por congruencia con la índole del asunto, de una atribución 
legal del ciclo entero de su «administración», comprensiva, pues, de la decisión final en dicho asunto).

Sin embargo, el acertado reconocimiento de la dificultad de la realización práctica del arquetipo (cuya construcción se inscribe más bien en la fase estática de la organización de las tareas públicas), en razón a las características mismas tanto de la sociedad industrial avanzada actual como del Estado plural (incluso en su organización territorial) que la institucionaliza, ha conducido -con toda lógica y ya en la perspectiva de la fase dinámica de la organización, es decir, del desarrollo y cumplimiento de las tareas públicas- a una diversificación legal interna de la categoría estudiada. Porque, en efecto, no es infrecuente (antes al contrario) ni que los intereses de colectividades territoriales superpuestos aparezcan entreverados, en distinta mezcla, en la vida social real, ni que las Administraciones públicas servidoras de tales intereses entren de diversa forma en contacto entre sí en el curso del ejercicio de sus competencias en principio (normativamente) deslindadas. De ahí, la previsión de la LRBRL de las siguientes variedades dentro de la categoría examinada:

1.1 Competencias propias, cuyo ejercicio se produce sin dar ocasión a contactos con la acción de otras Administraciones (por no hacerse presentes intereses públicos que incumban a éstas y que les motiven a actuar o porque, aun actualizándose tales intereses, la actuación de las otras Administraciones pueda producirse sin interferir aquel ejercicio).

Tal ejercicio de las competencias locales se produce uen régimen de autonomía y bajo la propia responsabilidad».

1.2 Competencias propias, con ocasión de cuyo ejercicio la acción de los entes locales incurre en una zona secante con la propia de otras entidades territoriales más amplias.

El solape entre los círculos de actuación de las Administraciones puede producirse de muy distintas formas, por lo que no es posible una solución legal única al supuesto; solución a la que la LRBRL efectivamente renuncia. De ahí la articulación de las fórmulas, de aplicación alternativa, que han de ser empleadas para el hallazgo en cada caso de la solución de fondo más adecuada:

1.2.1 En primer término (fórmula preferente), la cooperación o colaboración voluntarias negociadas, en su caso a través de mecanismos orgánicos formalizados (arts. 57 y 58 LRBRL).

Es claro que en esta hipótesis, la actuación y las decisiones locales precisas (al acuerdo de cooperación y a su ejecución) tienen lugar igualmente uen régimen de autonomía y bajo la propia 
responsabilidad", sin perjuicio de la vinculación a lo resuelto o establecido de mutuo acuerdo y de la posible intervención de técnicas blandas de persuasión (transferencias de fondos, subvenciones vinculadas, créditos con condiciones especiales, etc.).

1.2.2 En segundo lugar (fórmula alternativa), la coordinación impuesta (art. 59 LRBRL). Aquí no tiene lugar una limitación puntual (acto por acto) del ejercicio de la competencia local, sino una definición última y global (por relación a bloques orgánicos de materias o sectores administrativos) de los límites legales de la autonomía local, del marco dentro del que ésta ha de desenvolverse. Justamente la concreción de ese marco (en virtud de la autorización o remisión de la Ley) no excluye, sino que presupone la competencia local «enmarcada», y no implica, por ello, menoscabo de la misma (así lo ha hecho notar la STC 27/1987, de 27 de febrero). Por tanto, la competencia local coordinada se ejerce también -dentro del expresado marco- «en régimen de autonomía y bajo la propia responsabilidad». Este es el sentido del último párrafo del número 1 del artículo 59 LRBRL.

1.3 Competencias propias, que -por haber sido atribuidas en sectores cuya naturaleza no permite una configuración y asignación normativas diferenciadas y distintas de facultades decisorias- su ejercicio debe producirse, por definición, en el contexto de actuaciones o procedimientos conjuntos con otras Administraciones (art. 62 LRBRL).

Obsérvese que tampoco en este supuesto hay el más leve asomo de modulacion del régimen general de la competencia local propiamente dicha. Ocurre sólo que ésta no responde al tipo de competencia decisoria, teniendo un contenido y alcance menores. Pero ello es así como resultado de los términos de su configuración y atribución por la correspondiente norma legal. La competencia en sí misma considerada, tal como se encuentra legalmente diseñada, se ejerce en urégimen de autonomía y bajo la propia responsabilidad». A salvaguardar este régimen se dirige justamente la garantía del último párrafo del artículo 62 LRBRL.

\section{Competencias atribuidas (a medio de delegación: art. 7.3 LRBRL)}

En la medida en que esta categoría se nutre de la posibilidad de «transferencias competenciales» entre Administraciones, y presupone, por tanto, que la competencia es, en virtud de su configuración legal inicial, propia de Administración distinta a la local, el 
supuesto cae fuera de la problemática característica de las competencias locales.

El hecho de que el título en virtud del cual la competencia ha pasado a la esfera de la Administración local sea distinto del ordinario y complementario de la distribución legal originaria de competencias justifica la posibilidad de la modulación no ya del alcance, sino del contenido mismo de aquella competencia, de suerte que la actualización de aquél a través del ejercicio de ésta puede quedar mediatizada por decisiones directivas o controladoras de la Administración delegante.

Sin embargo, el contenido competencial efectivamente delegado y, por tanto, remitido - para su actuación- al ente local, queda sujeto obviamente al régimen general: las correspondientes actuaciones o decisiones se realizan en régimen de autonomía y bajo la propia responsabilidad. Sólo así se explica que, incluso en esta hipótesis, la LRBRL (art. 7.3) haga jugar la garantía del respeto de la potestad de autoorganización de los servicios de la entidad local.

Que lo delegado se cumpla en régimen de autonomía no sólo no es algo anormal, sino perfectamente congruente con la técnica de la delegación intersubjetiva. Pues a través de ella lo que se persigue es cabalmente el cumplimiento descentralizado de competencias originariamente centralizadas (en la Comunidad Autónoma o en la Administración del Estado) y, por tanto, el ejercicio de las mismas por las organizaciones locales conforme a su propio estatuto.

Este simple repaso a los principales supuestos deducibles de la tipología legal de las competencias locales corrobora plenamente la comprobación que al principio quedó hecha: todas las competencias conferidas, por uno u otro título, a los entes locales quedan sujetas, en los términos indicados para cada uno de los supuestos, a un mismo régimen jurídico, cuyo modelo es el arquetipo de las competencias propias, plenas y decisorias. Como consecuencia de su posición en el seno de un Estado único pero articulado sobre el pluralismo territorial, la Administracion local puede contar con más o menos, mayores o menores competencias, otorgadas a uno $u$ otro título y dotadas de un diverso alcance, pero el círculo que las mismas acoten en favor de aquélla aparece siempre organizado en la misma forma y con arreglo a la misma lógica de autonomía. De esta suerte, las relaciones entre la Administración local y las Administraciones de las comunidades territoriales superiores se entablan, desarrollan y resuelven siempre desde el respeto a dicha lógica, que nunca pueden mediatizar o vulnerar, no digamos anular. De ahí que, en último término, el sistema de relaciones interadministrativas no pueda cerrarse, para el supuesto de situaciones de 
conflicto irreductibles con las técnicas ordinarias puestas al servicio de aquéllas ( $y$ que deben ser respetuosas con el funcionamiento autónomo de lo que en cada caso sea local), sino con el recurso a la judicialización, como así hace -efectivamente- la LRBRL. Es precisamente la consecuencia con el principio de autonomía local la que conduce, en el vigente régimen local, a la reserva al poder judicial del papel de garante último de la operatividad de la descentralización local, en régimen de autoadministración, de las tareas públicas $y$ del cumplimiento de éstas de forma coherente con el conjunto de las asignadas a la Administración pública. La conexión entre el esquema de relaciones interadministrativas (el elenco de cuyas técnicas se agota en la información y lealtad recíprocas, así como en la cooperación, colaboración y coordinación) y el conflicto judicializado en la LRBRL se revela en la remisión que hace el artículo 64 al artículo 56.1.

Los términos en que se traba el conflicto son, naturalmente, bien distintos según los casos, pudiendo clasificarse en función de la iniciativa para su planteamiento:

A) Corresponde ésta al ente local, cuando:

a) El legislador no resuelve correcta o adecuadamente la atribución de competencias en una materia (privando injustificadamente a la Administración local de las que ya tuviere o no asignándole las que deberían corresponderle) o aborde la regulación de un sector concreto vulnerando el "estatuto local» establecido por la legislación de régimen local.

Se plantean en este punto muy importantes problemas, como los de la posición ordinamental de la legislación de régimen local (su relación con la sectorial) y las acciones atribuidas a la Administración local para la defensa de su autonomía (art. 63.3 LRBRL): problemas que, sin embargo, aqui no pueden ser abordados (aunque sobre el primero volveremos luego con algún detalle mayor) y que, sin duda, serán tratados en otras intervenciones de estas jornadas.

b) Las Administraciones habilitadas para coordinar la acción local incurren en exceso al precisar el marco concreto en el que debe desenvolverse ésta, constriñendo indebidamente su campo propio.

La legitimación local para impugnar en la vía contenciosoadministrativa las' correspondientes decisiones está claramente establecida en el artículo 63.2 LRBRL, debiendo-reconocerse a los entes locales, además y siquiera sea vía el derecho de petición que reconoce el artículo 29.1 de la Constitución, la posibilidad de solicitar el ejercicio de las facultades de control que los órganos 
parlamentarios se hayan reservado respecto al ejercicio de las de coordinación por los correspondientes ejecutivos.

c) La Administración del Estado o la de la correspondiente Comunidad Autónoma sustituyan indebidamente a un ente local en el cumplimientio de una tarea propia o, habiéndole sustituido, pretendan cargarle unos costes injustificados.

No ofrece duda la legitimación activa al amparo del artículo 63.2 LRBRL.

d) Las Administraciones delegantes actúen indebidamente las técnicas de dirección y control del ejercicio local de las competencias delegadas.

La legitimación activa de los entes locales está asegurada también en este caso por el artículo 63.2 LRBRL, toda vez que -según lo razonado hasta aquí- una dirección o un control incorrectos de las competencias delegadas provoca necesariamente una lesión de la autonomía local.

e) El Consejo de Ministros, en los términos del artículo 61.1 LRBRL, acuerde la disolución de los órganos de un ente local.

Nuevamente el artículo 63.2 LRBRL proporciona cobertura suficiente, con toda claridad, para la legitimación activa de la entidad afectada.

f) En general, los Gobiernos o las Administraciones del Estado o de las Comunidades Autónomas dicten disposiciones o produzcan resoluciones que incidan ilegítimamente en intereses gestionados por los entes locales.

Aquí la legitimación activa viene asegurada por la combinación de la regla especial del artículo 63.2 LRBRL con las generales contenidas en la Ley reguladora de la Jurisdicción ContenciosoAdministrativa.

B) ' Corresponde la iniciativa del conflicto, sin embargo, a la Administración del Estado o de la correspondiente Comunidad Autónoma, cuando los entes locales -actuando cualesquiera de sus competencias (propias en todas sus variantes o delegadas) o sin base competencial concreta- adopten acuerdos o produzcan actos que:

a) Atenten gravemente al interés general de España y no se haya atendido el requerimiento practicado para su anulación o reconsideración (art. 67 LRBRL).

Sin perjuicio de la facultad de suspensión en vía administrativa que se otorga al Delegado del Gobierno en la Comunidad Autónoma, el ejercicio de dicha facultad supone de suyo el conflicto judicial, al desencadenar el deber de impugnación del acuerdo o 
acto suspendido ante la Jurisdicción Contencioso-Administrativa en el plazo de diez días.

b) Excedan de la competencia del ente local o, en su caso, menoscaben competencias de alguna de las Administraciones superiores o interfieran su ejercicio (art. 66 LRBRL).

c) En general, incurran en infracción del ordenamiento jurídico (art. 65 LRBRL).

En los tres casos la legitimación activa para trabar el conflicto ante el Juez queda asegurada en el artículo 63.1, a), LRBRL.

Son estos últimos -atribuidos a la iniciativa de las Administraciones del Estado y de las Comunidades Autónomas- los que tienen mayor interés y plantean interrogantes, en tanto que:

- Es claro que integran, en el actual régimen local, las piezas sustitutivas de las técnicas de control o tutela administrativos tradicionales hasta la vigente Constitución.

- Son objeto de una regulación especial en dicho régimen local, en contraste con los que están remitidos a la iniciativa de los entes locales, los cuales dan lugar siempre a procesos enteramente regidos (salvo por lo que respecta a la legitimación activa) por la regulación adjetiva general u ordinaria de los mismos.

II. LA IMPUGNACION JUDICIAL POR LAS ADMINISTRACIONES ESTATAL $Y$ AUTONOMICA DE LOS ACTOS $Y$ ACUERDOS LOCALES

\section{Aspectos y cuestiones generales}

La LRBRL ha optado, como acabamos de ver, por excluir cualesquiera facultades de tutela directamente ejercitables por las Administraciones territoriales superiores en relación con actos o acuerdos locales producidos en el ámbito de actuación por éstos «en régimen de autonomía y bajo la propia responsabilidad». Por ello, ha articulado un sistema de impugnación judicial, a cuyos elementos hemos ya aludido, en el que se agotan las posibilidades de reacción por aquellas Administraciones territoriales superiores frente a dichos actos y acuerdos (el supuesto de atentado grave al interés general de España no constituye una excepción, pues la suspensión gubernativa se justifica en el carácter singular de dicho supuesto y la entrega del conflicto al Juez se produce inmediatamente. 
1.1 CARÁCTER CERRADO O ABIERTO DEL SISTEMA DE IMPUGNACIÓN Y POSIBILIDAD O NO DE SU DESARROLLO POR LA LEGISLACIÓN AUTONÓMICA DE RÉGIMEN LOCAL

El primer gran interrogante que suscita este régimen de impugnación de los actos y acuerdos locales es el de si agota y ultima la regulación de su objeto $o$, por el contrario, admite la convivencia con otros que lo modelen, es decir, autoricen reacciones en condiciones y términos específicos sobre la base de las peculiaridades de la materia o sector en la que se produzca el conflicto interadministrativo.

El simple examen, en su conjunto, de las disposiciones contenidas en el capítulo III del título $V$ de la LRBRL revela, sin lugar a dudas, la pretensión del texto legal de ordenar exhaustiva y completamente la cuestión, de suerte que el sistema resultante sea cerrado y único.

Este pertenece, en efecto, a la "constitución», al estatuto subjetivo de los entes locales, que es el ámbito propio de la norma local en su función de desarrollo del texto constitucional (téngase en cuenta que dicho estatuto establece la identidad del ordenamiento autónomo local y define la relación de éste con los ordenamientos superiores).

La integridad del régimen de impugnación analizado depende, así, de la relación entre la LRBRL y las restantes Leyes y, consecuentemente, de si las Leyes se ordenan entre sí exclusivamente por los principios de lex posterior, lex specialis y competencia o si, además, juega un papel el principio de su función constitucional, tal como postula la propia LRBRL en su Exposición de Motivos ( $« \ldots$ esa norma - la reguladora del régimen localdesarrolla la garantía constitucional de la autonomía local, función ordinamental que, al estarle reservada o, lo que es igual, vedada a cualesquiera otras normas, presta a su posición en el ordenamiento en su conjunto una vis específica, no obstante su condición formal de Ley ordinaria»), mantiene una corriente doctrinal emergente (vid. R. GÓMEZ FERRER Y MORANT, «Relaciones entre Leyes: competencia, jerarquía y función constitucional», RAP núm. 113, 1987; y el propio autor de estas líneas: L. PAREJO ALFONSO, "Derecho básico de la Administración local» Ed. Ariel, Barcelona 1988, cáp. II) y parece que comienza a sostener el Tribunal Constitucional (STC 72/1984, 14 de junio, sobre inelegibilidades e incompatibilidades de Diputados y Senadores).

Sin perjuicio de que pueda y deba postularse el juego efectivo del principio de función constitucional, es claro que dicho juego 
dista aún mucho de ser una realidad (si es que alguna vez llega a tenerla), por lo que la vigencia universal del sistema diseñado por la LRBRL está entregada a la racionalidad y disciplina del legislador.

Cuestión distinta, aunque conexa, es la de si la LRBRL puede ser objeto, en este punto, de un desarrollo por parte de las Leyes autonómicas de régimen local. Estas Leyes son piezas integrantes del ordenamiento local y no elementos ajenos al mismo, pero la doble circunstancia de tratarse de una regulación básica con vocación de completa o cerrada (por encontrarse implicada la definición misma de la autonomía local en su relación con los otros ordenamientos territoriales) y tener por objeto dicha regulación la determinación de las condiciones en que se traba en cada caso el conflicto judicial entre tales ordenamientos (materia, la de la legislación procesal, que está reservada al legislador estatal) obliga a una respuesta negativa. No es ésta, sin embargo, la solución que se comienza a imponer en la práctica, a juzgar por la Ley catalana número 8 , de 15 de abril de 1987, cuyos artículos 165 y 166 introducen "adaptaciones» (aunque ciertamente ligeras) al régimen establecido en la LRBRL. El camino así abierto por el legislador catalán en modo alguno puede considerarse correcto.

\subsection{CONSTRUCCION INTERNA DEL RÉGIMEN DE IMPUGNACIÓN DE LOS ACTOS Y ACUERDOS LOCALES SOBRE LA BASE DE LA DIFERENCIACIÓN. DE SUPUESTOS}

El régimen de impugnación de actos y acuerdos no constituye sino una parte, aunque la principal, del sistema legal de relaciones entre las instancias estatal y autonómica, de un lado, y la local, de otro; relaciones condicionadas por el carácter específico de la autonomía de ésta última y derivadas de la necesidad, por tanto, del arbitrio de mecanismos dirigidos a hacer efectivos en todo momento los límites inherentes a dicha autonomía. En definitiva, ese sistema de relaciones está al servicio de los principios de coordinación $y$ eficacia consagrados en el artículo 103.1 de la Constitución, en cuanto procura el funcionamiento coherente de las Administraciones públicas (en este caso mediante el impedimento de que la local extravase sus límites propios, así como el aseguramiento de que la misma realiza en el plano administrativo la legislación emanada de las instancias superiores). Desde esta perspectiva más amplia, la regulación legal descansa sobre la distinción entre conductas políticas o gestiones globalmente consideradas, de una parte, $y$ actos o acuerdos, es decir, decisiones concretas, de otra. 
El primero de estos dos planos es abordado y tratado en el marco de las relaciones interadministrativas, dando lugar al apoderamiento al Gobierno de la Nación con una competencia de disolución de los órganos de los entes locales, lo que vale decir a la previsión de un mecanismo de control gubernativo de la actividad de estos entes. La LRBRL no judicializa por entero, consecuentemente, las relaciones de la Administración local con las instancias territoriales superiores, por más que el supuesto en que se traduce el plano considerado, la "gestión gravemente dañosa para los intereses generales que suponga el incumplimiento de [sus] obligaciones constitucionales» (art. 61 LRBRL), sea ciertamente excepcional.

El segundo de los planos antes precisados es el que la LRBRL adopta para someter las correspondientes relaciones al principio de judicialización en caso de conflicto. Quiere decirse así que el régimen de impugnación comprende sólo conflictos derivados de actos o acuerdos concretos, pero también cubre todos los que se susciten con motivo de decisiones locales determinadas, sean particulares (actos administrativos), sean disposiciones (Reglamentos y Ordenanzas). En contraste con el plano anterior, aqui la LRBRL diferencia varios supuestos. Esta diferenciación objeto de crítica por la doctrina responde en último término a la razón y la funcionalidad mismas - ya indicadas-del sistema de relaciones y se establece, por ello, en función de la índole de la extralimitación de la autonomía a que el acto o el acuerdo dé lugar, es decir, de la mayor o menor perturbación que dicha extralimitación represente del ordenado y coordinado funcionamiento de las Administraciones públicas: atentado grave al interés general de España (art. 6.7 LRBRL); infracción del orden de competencias (art. 66 LRBRL) e infracción sustantiva del ordenamiento (art. 65 LRBRL).

Esta tipificación de supuestos y la consecuente diversificación del régimen del conflicto ha sido objeto de crítica desde el primer momento por la doctrina [por relación al precedente de la Ley 40/1981, de 28 de octubre, A. FANLO LORAS: «Problemática actual del control de legalidad de los actos y acuerdos de las Corporaciones locales. Estudio de los artículos 8 y 9 de la Ley 40/1981, de 28 de octubre», en la obra colectiva Organización territorial del Estado (Administración local), Ed. IEF, Madrid, 1985, vol. I, pp. 1147 y ss., en relación con el proyecto de Ley Reguladora de las Bases del Régimen Local, G. FernÁNDEZ FARRERES: «El control por el Estado y las Comunidades Autónomas de los actos y acuerdos de las Entidades Locales en el proyecto de Ley Reguladora de las Bases del Régimen Local de 1984», en la misma obra colectiva, vol. I, pp. 12.13 y ss.; ya con respecto a la Ley vigente, A. NIETo: 
«Impugnación jurisdiccional de actos y acuerdos de las entidades locales», RAP núm. 115, y J. BERMEJO VERA, aunque éste de forma más matizada: «El control de las decisiones locales», en la obra colectiva Tratado de Derecho municipal, Ed. Civitas, Madrid, 1988, vol, l, pp. 531 y ss.]. Aparte la imputación de ser tributaria de la regulación, reputada defectuosa, contenida previamente en la Ley 40/1981, de 28 de octubre, las objeciones principales se centran en los supuestos de infracción del orden de competencias y del ordenamiento sustantivo, puesto que el basado en atentado grave al interés general de España no se cuestiona tanto por su diferenciación como por los términos de su definición (por lo que el análisis de la crítica a este último puede quedar ahora remitida al momento posterior del estudio individualizado de los distintos supuestos). Sintetizando mucho, tales objeciones destacan:

a) La artificiosidad de la distinción entre infracción del ordenamiento jurídico e infracción del orden competencial, pues ésta no es sino una variedad de aquella otra más general. Reproduce, así, la LRBRL las dificultades de interpretación y aplicación que ya se habían revelado bajo la vigencia de la Ley 40/1981.

b) La escasa diferencia de las consecuencias que, en cuanto al régimen concreto de la impugnación, se hacen derivar de la anterior distinción de supuestos. Con ello, se dice, no hace sino agravarse el defecto de la artificiosidad del deslinde de ambos supuestos, al no existir proporción entre la problematicidad de éste y sus efectos jurídicos.

No puede dejar de observarse que en la valoración, en este punto, de la LRBRL, la doctrina -al menos en la mayoría de los casos- parece dominada por una cierta decepción por la que entiende escasa novedad de la opción legal (medida a la luz de la doctrina del Tribunal Constitucional y de las medidas de desmantelamiento de las técnicas de tutela que habían culminado en la Ley $40 / 1981$, de 28 de octubre), así como por el que juzga exceso en la valoración de las exigencias de la autonomía local. Esa decepción puede estar justificada desde una posición, perfectamente legítima, que defienda la posibilidad y aún la conveniencia de técnicas de control más enérgicas, al menos para algunos casos, y sirve, por tanto, para expresar un juicio global negativo sobre la judicialización por la que se ha inclinado el legislador, pero no parece de recibo que se proyecte sobre el análisis mismo de la regulación legal. Como no podía ser de otra forma, ésta ha debido tener en cuenta la Ley $40 / 1981$, de 28 de octubre, pero en modo alguno se ha limitado a incorporar al nuevo régimen local sus artículos 8 y 9 , por 
lo que la regulación vigente no puede medirse por el rasero de tales preceptos.

La objeción de la artificiosidad de la distinción entre infracción del ordenamiento e infracción del orden competencial no resiste un serio análisis, más allá del terreno propio de la valoración del acierto en la formulación técnica concreta de cada uno de los dos supuestos. Es claro que la infracción del orden competencial es, en último término, una variedad del género de infracción del ordenamiento jurídico, pero este modo de proceder es el usual en Derecho. También en el terreno de la invalidez de los actos administrativos, la nulidad constituye únicamene una variedad de la categoría más amplia de la anulabilidad, en la medida en que ésta cubre cualquier infracción del ordenamiento jurídico, y a nadie le ha parecido que la diferenciación de unos determinados vicios en razón a su intensidad o gravedad sea una artificiosidad carente de justificación. Más aún, justo para conflictos entre instancias territoriales (aunque otras distintas: entre el poder central y las Comunidades Autónomas) la Ley Orgánica del Tribunal Constitucional ha implantado una solución igualmente articulada en la diferenciación entre aquellos que versan sobre la competencia y aquellos otros que se refieren a la conformidad o no a [derecho al bloque de la constitucionalidad] de las decisiones públicas, sin que la doctrina haya encontrado tampoco en este caso motivo para una crítica similar a la que se hace a la LRBRL.

En definitiva, la solución de esta última responde a una lógica elemental, que no puede verse empañada por el hecho de que haya inspirado también a la Ley $40 / 1981$, de 28 de octubre. Desde la óptica del objetivo de garantizar la observancia de los límites inherentes a la autonomía local, el conflicto entre las instancias estatal o autonómica (llamadas a hacer efectivos dichos límites) y la local sólo puede trabarse por dos razones pefectamente distintas y deslindables: o bien la Administración local excede o rompe el orden competencial (lo que nada dice necesariamente acerca de la conformidad o disconformidad a Derecho, en cuanto al fondo, de la decisión o la omisión locales), o bien produce acuerdos $o$ actos que material o sustantivamente infringen la legalidad aplicable a los mismos (actos o acuerdos para los que, en este caso, pueden ser perfectamente competentes $-y$ ello será lo normal- los entes locales). Todos los supuestos posibles de conflicto se dejan encuadrar en una u otra de tales hipótesis. $Y$ la clasificación de los conflictos en función de su diferenciación es la más congruente con el fundamento mismo del régimen de impugnación examinado, que no es otro que el aseguramiento de la 
coordinación de la Administración local en el conjunto de la Administración pública, pues aquella clasificación refleja la específica gradación que -desde el punto de vista del impacto en dicha coordinación- cabe establecer en el funcionamiento incorrecto del ordenamiento local. Es claro que la infracción del orden competencial tiene mayor trascendencia, en cuanto por sí misma pone en cuestión los límites que marcan el ámbito de la autonomía local $(y$. en principio, para una serie indeterminada de actos). Ello no sucede en la simple disconformidad a Derecho de un acto o acuerdo, ya que en ella únicamente está en juego la integridad y efectividad -en el supuesto de que se trate- de la norma conculcada $y$, sólo a través de ella y para el caso concreto, la del límite a la autonomía local que sustantivamente expresa. Por tanto, y desde la perspectiva adoptada, no es igual discutir sobre la competencia para adoptar determinadas decisiones, que hacerlo sobre la conformidad o no a Derecho de una decisión en concreto. En el primer caso se hace presente un interés estructural, el de mantener a la autonomía local en sus límites como condición para el correcto funcionamiento del sistema administrativo en su conjunto. En el segundo, y de ordinario, sólo actúa un interés objetivo por la efectividad de la legislación sustantiva emanada de las instancias superiores y constitutiva del marco que la autonomía local no sólo ha de respetar, sino sobre todo integrar y realizar.

En conclusión, pues, la clasificación que opera la LRBRL no sólo no parece artificiosa, sino que se ofrece como la más congruente con la finalidad propia del régimen de impugnación de los actos locales por las Administraciones superiores, sin perjuicio de que la definición legal de cada una de las dos clases de conflictos pueda no ser técnicamente la mejor posible. La deficiencia técnica en la definición de los supuestos no significa, sin embargo, que deba haber especial dificultad para su correcta elección y aplicación, toda vez que es claro el ámbito propio de cada uno de ellos.

La segunda de las objeciones, que hace hincapié en la escasa diferencia de las consecuencias jurídicas que la Ley extrae de la anterior clasificación de los conf́lictos, no merece mejor opinión. Aquí es donde más se irasluce la decepción ante la que se estima poca energía de los mecanismos de reacción frente a la extralimitación local, que es argumento que sólo tiene sentido frente a la opción legal en favor de la judicialización. Porque lo cierto es que la Ley modula y diversifica el régimen de la impugnación, atendiendo justamente a la gradación resultante de la gravedad de la perturbación que, en la coordinación de la Administración pública en su conjunto, ocasione aquella extralimitación. 
Justamente por ello, el supuesto consistente en un atentado grave al interés general de España se configura a caballo entre un control gubernativo y judicial. La reacción inicial frente a la extralimitación legal (que es administrativa) no sólo enerva la eficacia del acto o acuerdo local, sino que comprende la posibilidad de la adopción positiva de medidas (administrativas) dirigidas a la protección del bien lesionado por dicho acto o acuerdo. Luego el conflicto se judicializa preceptivamente, pero una vez que la situación jurídica ha sido alterada por las medidas adoptadas por la Administración del Estado.

La infracción del orden competencial autoriza la impugnación judicial directa, en plazo brevísimo, del correspondiente acto o acuerdo y a solicitar y obtener, con motivo de la misma, la suspensión de éste conforme a un régimen específico.

Finalmente, la simple infracción, en cuanto al fondo, del ordenamiento jurídico recibe un tratamiento equiparable, sin perjuicio de las especialidades derivadas del hecho de que quien impugna sea otra Administración (requerimiento previo optativo, posibilidad de la impugnación directa sin previo recurso), al propio de la impugnación judicial ordinaria de los actos administrativos, incluso en lo referente a la medida cautelar de la suspensión.

No puede decirse, pues, que la clasificación legal de los conf́lictos no dé lugar a una diversificación del régimen jurídico de la impugnación de los correspondientes actos o acuerdos locales, ni que ésta diversificación no sea congruente con la filosofía general del sistema de conf́lictos o no guarde proporción con la complicación que la misma clasificación de éstos supone. La proporción existe desde luego, como resulta sin más de la anterior sintética descripción de los distintos supuestos. Ocurre sólo que la Ley asume como principio o regla la judicialización; dato del que no puede prescindirse a la hora de enjuiciar las diferencias, por ejemplo, en punto a suspensión de la eficacia de los actos o acuerdos impugnados, entre los supuestos de los artículos 65 y 66. Unicamente tomando como referencia el modelo del efecto suspensivo automático de la reacción, incluso en vía administrativa, frente a los actos locales, puede entenderse que se considere que son escasas las diferencias en el régimen de la impugnación ex artículo 65 y 66 LRBRL.

\subsection{INCLUSIÓN DE UN RÉGIMEN ESPECÍFICO DE LEGITIMIACIÓN ACTIVA}

Ha llamado la atención de la doctrina el hecho de que la LRBRL regule expresamente la legitimación activa para trabar el conflicto tanto en los supuestos en que la iniciativa de éste corresponde a 
los entes locales, como en aquellos en los que dicha iniciativa pertenece a las Administraciones estatales y autonómica. Aunque en general el juicio de esta regulación es favorable, algún autor [A. NIETO], sin llegar a una opinión totalmente negativa, mantiene que, en realidad, es superflua, por bastar la regulación general contenida en la legislación procesal.

Aquí también se evidencia un claro exceso de rigor en la doctrina, tanto más cuanto que ese rigor se aplica desigualmente (en este caso, el efecto en todo caso clarificador de la regulación legal debería llevar, siguiendo la lógica aplicada a los preceptos ordenadores del sistema de impugnación, a un juicio netamente favorable). La finalidad de la regulación y su justificación son, sin embargo, claras; aún cuando el régimen general de la legitimación hubiera podido en teoría bastar, la doble circunstancia de estar éste articulado sobre el concepto de interés y comprender el sistema de impugnación supuestos en que el interés es "objetivo» (significativamente el contemplado en el artículo 65 LRBRL), la construcción acabada del sistema exigía (y no sólo aconsejaba) despejar cualquier duda acerca de la actuación de todos y cada uno de los mecanismos del mismo, en lo que aquí interesa, por las Administraciones estatal y autonómica.

La experiencia facilitada por la jurisprudencia no sólo del Tribunal Supremo, sino también del Tribunal Constitucional en punto al interés de una Administración o instancia territorial a efectos de legitimarla para impugnar disposiciones o actos de otra acreditaba la imposibilidad de fiar el funcionamiento correcto del sistema a la interpretación del círculo de interés legítimo de las Administraciones estatal o autonómica (como, a la inversa, de la local).

Se está, pues, ante unas prescripciones legales que, además de no ser superfluas y tener una utilidad en todo caso de clarificación de la legitimación activa a efectos de actuación del régimen de impugnación de actos locales, constituyen una pieza necesaria para asegurar el correcto funcionamiento de éste último conforme a su diseño legal.

\subsection{CONFLICTO ENTRE ADMINISTRACIONES Y DEFENSA DE LOS DERECHOS E INTERESES DE LOS PARTICULARES AFECTADOS POR EL MISMO}

El régimen de impugnación específico aquí analizado está establecido desde la perspectiva del conflicto entre dos Administraciones públicas y no incorpora expresamente previsión alguna de su incidencia sobre los derechos e intereses legítimos de los particulares que pudieran verse afectados por el desenlace de la 
impugnación. Agudamente la doctrina [A. NIETO, J. BERMEJO] se ha planteado los problemas derivados de esa incidencia, proponiendo soluciones para los mismos.

La posibilidad e, incluso, la normalidad de la aludida incidencia es incontestable, pues los conflictos entre Administraciones que nos ocupan se producen siempre con motivo de un acto o acuerdo local (por ello el conflicto se formaliza como una impugnación de éste) y no será en absoluto infrecuente que dicho acto o acuerdo tenga unos precisos beneficiarios. En tal hipótesis el desenlace de la impugnación (la confirmación o la anulación del acto o acuerdo) afecta necesariamente a tales beneficiarios, así como a todas cuantas personas hayan intervenido como interesadas en el procedimiento administrativo resuelto justamente por el acto o el acuerdo impugnado. Consecuentemente, el desarrollo del conflicto $y$, por tanto, de la impugnación no podrá producirse sin dar ocasión a los beneficiarios del acto o acuerdo y los terceros interesados para defender sus derechos e intereses legítimos.

La LRBRL, centrada su atención en la relación entre las Administraciones estatal o autonómica y la local, no contempla la llamada a los particulares afectados o interesados, circunstancia que -en sí misma- no es merecedora de crítica. Pues esa falta de previsión no origina problemas interpretativos de difícil solución. En definitiva, el conflicto regulado por la Ley, cuando no da lugar sin más a una impugnación $y$, por tanto, un proceso judicial, presenta una formalización en vía administrativa que o bien no es compatible con la intervención de terceros dada su excepcionalidad o bien se traduce en un procedimiento al que son de aplicación las reglas, los principios y las técnicas generales del procedimiento administrativo. El examen de los distintos supuestos permite concretar más las soluciones idóneas:

a) El conflicto de menor entidad -regulado en el artículo 65 LRBRL- puede desarrollarse de dos formas distintas, según que la Administración que adopte la iniciativa opte o no por formular un requerimiento de rectificación al ente local correspondiente.

En el primer caso, el conflicto se despliega, en su caso, en dos fases: una administrativa y otra judicial. En la medida en que la fase administrativa da lugar a un verdadero, aunque breve, procedimiento (formulación del requerimiento y contestación al mismo) y en éste la contestación al requerimiento no tiene un plazo preestablecido por la Ley, parece claro que - de haber terceros interesados- su llamada al procedimiento y el otorgamiento a los mismos de trámite de alegaciones no deben ofrecer dificultad alguna, en tanto que el plazo a conceder al ente local por la Administración 
requirente -aunque nada diga la Ley- nunca podrá ser inferior al que ésta otorga a aquélla (15 días hábiles) justamente para requerir. La fijación de un plazo menor a éste para responder al requerimiento, al implicar un desequilibrio en favor de éste y en detrimento de la defensa de la entidad local, habría de calificarse de irrazonable $e$ injustificado $y$, por tanto, ilegal. Pues la indeterminación en que la Ley deja el plazo en cuestión obedece claramente a la apreciación de que su duración deberá ser, de ordinario, mayor a la del requerimiento, atendidas las características de la organización y el funcionamiento interno de las entidades locales, la naturaleza del acto objeto del requerimiento y las circunstancias del caso concreto.

Así pues, incluso en la hipótesis más extrema de fijación del plazo de contestación en quince días la regulación legal no entra en contradicción con el obligado trámite de audiencia a los terceros interesados (que sería de diez días), por más que el tiempo disponible es ciertamente ajustado. La solución idónea consistiría en que la propia Administración requirente modulara, al fijarlo, la duración del plazo, ororgando una específica ampliación del mismo para el caso de existir terceros interesados y ser éstos notificados del procedimiento (con otorgamiento de trámite de alegaciones).

Si la Administración estatal o autonómica prescinde del requerimiento y decide impugnar directamente el acto o el acuerdo ante la Jurisdicción Contencioso-Administrativa, el problema queda resuelto sin más. Pues en nada diferirá el caso ordinario en el que cualquier persona que se considere perjudicada por el acto o acuerdo local deduzca recurso contencioso-administrativo contra el mismo: deducido éste, habrá de emplazarse a cuantas personas cuenten con derechos $o$ intereses legítimos que pueden resultar afectados por la Sentencia que ponga fin al proceso.

b) En el conf́licto contemplado por el artículo 66 LRBRL (infracción del orden de competencias) no existe actuación alguna en vía administrativa. La Administración estatal o autonómica procede directamente a impugnar el acto o acuerdo local que estime viciado de incompetencia ante la Jurisdicción ContenciosoAdministrativa, aún cuando alguna opinión doctrinal considere que es posible la anteposición de un requerimiento administrativo (sobre este punto se volverá al tratar individualizadamente cada uno de los supuestos legales).

No hay aqui, por tanto, problema alguno. Planteada la impugnación, todos los interesados deberán ser llamados al proceso.

c) Mayor complicación, al menos aparentemente, ofrece el conflicto previsto en el artículo 67 LRBRL. Bien es verdad que, dadas sus características, difícilmente tendrá por objeto actos o 
acuerdos con unos concretos beneficiarios. Aun asi, la simple posibilidad de que también en este caso se produzca una incidencia en derechos o intereses de terceros obliga a plantearse la cuestión de la defensa de los mismos.

La estructura del conflicto es similar a la del regulado en el artículo 65 LRBRL: doble fase administrativa y judicial (sólo que ahora la primera no es soslayable) y articulación de la administrativa en un requerimiento y su contestación. Ocurre, sin embargo, que se está ante el supuesto de conflicto más grave de los contemplados por la Ley $y$ que, por ello, demanda una inmediata composición (siquiera sea provisional) en vía administrativa. De ahí el apoderamiento a la Administración del Estado (y sólo a ella) para adoptar por sí misma (trabado sin avenencia el conflicto) medidas de composición, si bien no definitivas y sí sólo cautelares: suspensión del acto o acuerdo local, disposiciones de protección del interés general. La excepcionalidad del supuesto, la urgencia que en él está implícita y la naturaleza puramente cautelar del desenlace administrativo del conflicto, obligan a estimar que el desarrollo de esta fase debe ser rápido y no verse dificultado por la discusión de fondo de los eventuales derechos o intereses que del acto local pudieran haberse derivado para terceros. La improcedencia, como regla general, de un trámite de alegaciones de éstos se justifica en el contenido del mismo del conflicto en vía gubernatvia, que no alcanza a decisión alguna definitiva sobre el fondo, moviéndose en el plano de las medidas provisionales. Así resulta de un triple dato:

- El destinatario del requerimiento es siempre el Presidente de la Corporación local (la precisión del órgano es significativa por comparación con la regulación de los otros conflictos) a pesar de que no siempre será él el competente para reconsiderar el acto o acuerdo.

- Las medidas con que el Delegado del Gobierno puede responder a la no atención del requerimiento no operan en el plano de la validez del acro o acuerdo local.

- La fase judicial tiene un contenido propio, perfectamente definido, que sí comprende ya la discusión de la validez del acto o acuerdo local.

Por lo ranto, la solución antes apuntada es, sin duda, la más conforme con la índole del conflicto (en vía administrativa) y su tratamiento legal, no suponiendo una vulneración del principio inaudita parte. La defensa de los derechos e intereses de los terceros af́ectados tiene su momento y su lugar adecuados en la fase judicial en la que necesariamente tiene que desembocar el 
conflicto, toda vez que dichos terceros deberán ser emplazados para comparecer en el proceso.

Con lo dicho no quedan resueltos, no obstante, todos los problemas que el artículo 67 LRBRL suscita en este orden de cosas. Pues en la hipótesis en que el Presidente de la Corporación local, por poder hacerlo, acepte el requerimiento, se habrá producido ya en ese momento una reconsideración del acto cuestionado, sin que se hubiera oído previamente a los particulares afectados.

El caso planteado raramente podrá tener lugar. Como ha quedado razonado, la regulación legal pretende únicamente -ante una situación excepcional y grave, que no puede prolongarse en el tiempo- una composición provisional inmediata en sede administrativa, sin perjuicio del ulterior debate pleno y de fondo en sede judicial. Por tanto, debe entenderse que la atención al requerimiento ni tiene que, ni debe consistir en una anulación del acto o acuerdo local, alcanzando sólo al plano de su eficacia. De lo que se trata es que el atentado grave al interés general de España que se imputa a la decisión local no se materialice, es decir, que no se consuma dicho atentado hasta tanto no se haya producido el control judicial de su conformidad a Derecho. Ahora bien, nada impide, en efecto, que habiendo emanado el acto del propio Presidente de la Corporación, éste vuelva sobre el mismo con motivo del requerimiento. Semejante reconsideración del acto no podrá tener lugar, en tal caso, sin previamente oír -si los hay- a los terceros interesados. Sólo, pues, si el plazo otorgado al efecto permite el otorgamiento del trámite de audiencia (para lo cual cabría, en su caso, reducir el plazo legal ordinario de diez días, por razón de urgencia, a la mitad) y si dicho trámite se concede efectivamente podría admitirse una anulación por la propia entidad local de su decisión. El modo de proceder normal será, por el contrario, el siguiente:

- Aceptación del requerimiento y adopción de las medidas provisionales o cautelares precisas.

- Incoación del pertinente procedimiento para la anulación del acto o acuerdo; procedimiento al que deberán ser llamados los particulares interesados.

\subsection{CONEXIÓN ENTRE RÉGIMEN LOCAL Y LEGISLACIÓN CONTENCIOSO-ADMINISTRATIVA}

El régimen que de la impugnación de los actos y acuerdos locales por las Administraciones estatal y autonómica establece la LRBRL se centra, en la medida de lo posible, en la fase administrativa de los correspondientes conflictos, pero incide inevitablemente 
-tanto más cuanto que la opción legal es la de judicialización de dichos conflictos- en su planteamiento contencioso-administrativo.

Esa inevitable incidencia forzosamente se presentaba con perfiles problemáticos: la LRBRL innovaba el ordenamiento local desde el principio constitucional de autonomía, lo que significaba el desmantelamiento de las técnicas de tutela que habian repercutido, al menos en algún caso, en el proceso contencioso-administrativo; por su parte, la Ley reguladora de la Jurisdicción ContenciosoAdministrativa continuaba vigente -con ligerísimos retoques- en su versión de 1956.

La opción del legislador de régimen local, a la vista de los artículos 65, 66 y 67 LRBRL, puede sintetizarse así:

- No modificación puntual, desde el régimen local, de la Ley reguladora de la Jurisdicción Contencioso-Administrativa, con la única excepción -a todas luces inevitable- del incidente de suspensión a que se refiere el artículo 66 .

- Remisión en todos los casos al procedimiento ordinario del recurso contencioso-administrativo.

Que los conflictos contemplados en los artículos 65 y 66 LRBRL desembocan en un recurso contencioso-administrativo ordinario parece fuera de duda. En los dos supuestos las Administraciones estatal y autonómica impugnan sin más los correspondientes actos o acuerdos locales. La Exposición de Motivos de la Ley es clara al respecto: "naturalmente que el cuadro de técnicas (se refiere a las articuladas al servicio del sistema de relaciones interadministrativas) ha de cerrarse por un sistema resolutorio del supuesto límite del conflicto, por fracaso de las mismas. La configuración de ese sistema de conflictos tiene que ser, a la vez, respetuosa con la esencial igualdad posicional de las Administraciones territoriales y aseguradora de que el planteamiento y la sustanciación del conflicto no alteran la específica estructura constitucional de los intereses públicos a los que sirven dichas Administraciones.»

Más dudoso resulta en principio el caso del artículo 67 LRBRL. Pero quizá la duda obedezca sólo a la apariencia de reenvío al procedimiento especial del artículo 118 de la Ley reguladora de la Jurisdicción Contencioso-Administrativa que provoca el empleo de la técnica de la suspensión por el Delegado del Gobierno del acto o acuerdo local. Pero esa apariencia se diluye inmediatamente con sólo considerar que en el artículo 67 LRBRL no son las medidas adoptadas en vía administrativa por dicho Delegado (el «traslado de la suspensión» en terminología del artículo 118 de la LJCA) las que 
ponen en marcha el proceso judicial. Antes, al contrario, éste aparece formalmente desligado de aquéllas, pues el precepto legal se cuida de imponer al propio Delegado el deber inexcusable de impugnar los mismos actos y acuerdos que previamente ha suspendido. Se trata, pues, también aqui de una impugnación, de un recurso que interpone la Administración del Estado por intermedio del Delegado del Gobierno, que tiene por objeto el acto o acuerdo local correspondiente (y no las medidas provisionales de aquel Delegado, lo que sea dicho de paso confirma el carácter meramente cautelar de las mismas). El procedimiento a seguir no es otro, por tanto, que el ordinario.

\section{Los distintos supuestos lagales}

\subsection{EL CONFLICTO Y LA IMPUGNACION DEL ARTICULO 65 LRBRL (ARTS. 214 Y 215 ROFRJEL)}

Como ya nos consta, este es el supuesto de conflicto más genérico e inespecífico, expresivo de un control (hecho efectivo, sin embargo, básicamente en sede judicial) de los ordenamientos territoriales superiores sobre el local y fundamentado en la necesidad del aseguramiento de la observancia por este último de sus límites propios. El objeto del conflicto es, sencillamente, la infracción del ordenamiento jurídico y, más concretamente (como resulta sin más de una interpretación sistemática que ponga en relación el supuesto con el previsto en el artículo 66 siguiente) la infracción sustantiva y directa del mismo (bien sea de normas estatales stricto sensu, bien sea de normas autonómicas). La posibilidad del surgimiento de conflicto sobre tal extremo reposa en un control general sobre las decisiones locales, que -a su vez-deriva de la obligación de comunicación a las Administraciones del Estado y de la respectiva Comunidad Autónoma de la totalidad de los actos y acuerdos adoptados (art. 56 LRBRL); obligación que constituye una especificación peculiar en este campo del deber genérico de información sobre la propia gestión (relevante para el eficaz cumplimiento de las tareas de las otras Administraciones) que se impone a los tres niveles administrativos en presencia (art. 55, c), LR8RL). La respuesta a la estimación, como resultado del ejercicio del indicado control, de la comisión de un infracción legal -respuesta que traba el conflicto-, puede ser indistintamente, a elección de la Administración actuante, la directa impugnación judicial o la formulación de un requerimiento administrativo de anulación del acto o acuerdo reputado ilegal. En el primer caso, el 
control se traduce sin más en el ejercicio de la correspondiente acción judicial y la deducción de la pertinente pretensión en el marco del proceso contencioso-administrativo así entablado. En el segundo, el control da lugar inicialmente a un conflicto estrictamente administrativo, de cuyo desenlace depende la judicialización del mismo. Pero en la hipótesis en que tenga lugar, la judicialización se produce en términos idénticos a la impugnación judicial directa (con la sola salvedad de que la impugnación lo será también del acto expreso o presunto de no aceptación del requerimiento).

Además de las cuestiones de índole general ya analizadas, el supuesto legal así esquemáticamente determinado, suscita algunos problemas específicos $y$, en concreto, los que a continuación se pasa a examinar.

\subsubsection{La excepción del agotamiento de la vía administrativa mediante la formulación del pertinente recurso.}

En la medida en que el artículo 65 LRBRL se ha limitado a prever la doble posibilidad de la impugnación judicial directa o previo requerimiento, puede suscitarse el interrogante de si dicha impugnación está o no debidamente excepcionada del requisito del recurso administrativo, toda vez que la exclusión expresa de éste sólo se contiene en el artículo 214.2 ROFRJEL (precepto éste que carece de rango legal formal preciso para excepcionar lo dispuesto en los artículos 52 y 53 LJCA). Así lo hace A. NiETo (op. cir.), para quien la cuestión se resuelve en sentido positivo entendiendo, como debe hacerse, que la regulación reglamentaria hace explícito un contenido dispositivo implícito en el texto legal básico del régimen local. En realidad, tanto el planteamiento mismo de la cuestión como su resolución en los términos indicados son un tanto excesivos. Porque sólo desde una interpretación formal y atenida al artículo 65 cabe hablar de una falta de previsión legal. La LRBRL ha establecido un diseño nuevo y completo de las relaciones de conflicto entre las Administraciones del Estado y autonómicas, de un lado, y la local, de otra; cuadro de relaciones, del que el supuesto examinado constituye una de las piezas componentes. $Y$ de la regulación de dicho cuadro, que con toda evidencia pretende ser completa, se infiere sin duda razonable que el requisito del recurso administrativo previo, en concreto el de reposición, no juega, ni puede jugar. En la opción del requerimiento ello es así, porque el propio mecanismo del requerimiento excluye de suyo el recurso, so pena de perder todo su sentido. De esta suerte, en la opción alternativa basta para dicha exclusión la previsión del carácter directo de la impugnación judicial; tanto más, cuanto que 
el empleo de la expresión uimpugnación directa» con parejo significado no le es desconocida a la LJCA [véanse los artículos 39.1 y 3 y $53, e)$, de la misma: impugnación directa de disposiciones de carácter general no precisadas, para su efectiva aplicación. de acto de requerimiento o sujeción individual].

\subsubsection{La virtualidad del requerimiento en orden a la devolución al ente local de la potestad de anulación de sus actos o acuerdos.}

Ninguna duda ofrece (sobre todo, por lo que hace a la Administración local, después de la definitiva clarificación de la aplicación a la misma de la legislación general sobre procedimiento administrativo, operada por el artículo 149.1.18 de la Constitución) que la Administración no puede volver sobre sus actos sino en virtud de recurso (enervante de la firmeza de aquéllos), o, en su caso, de la potestad de revisión en supuestos tasados regulada en los artículos 109 y 110 LPA. De esta comprobación elemental y del dato de que el artículo 65 LRBRL no contenga un apoderamiento específico y positivo a la Administración local requerida para la anulación del acto $o$ acuerdo que motiva el conflicto no parece, sin embargo, que pueda hacerse seguir razonablemente la duda de si efectivamente dicha Administración cuenta, en el supuesto legal considerado, con la indicada potestad de anulación (cual hace, también aquí, A. NiETO op. cit.).

La duda se plantea desde la afirmación de que la Ley no ha atribuido la potestad, de suerte que la previsión que al efecto se contiene en el artículo 215.3 ROFRJEL es simplemente reglamentaria $y$, por tanto, insuficiente para otorgar adecuada cobertura a la efectiva anulación de las propias decisiones en virtud de un requerimiento formulado por otra Administración, cuyos efectos no están legalmente precisados. La solución entonces únicamente puede provenir (es efectivamente la que propone A. NIETO) de la aplicación analógica al caso del artículo 119 LPA, fundada en el paralelismo funcional existente entre el requerimiento y el recurso administrativo.

Frente a esta construcción doctrinal, cabe argumentar:

- La finalidad institucional del sistema de relaciones de conflicto, que no es otra -para decirlo gráficamente- que la de ocupar en el nuevo régimen local la posición que, en el anterior, correspondía a la tutela. Desde esta perspectiva es claro que los actos y acuerdos de los entes locales no alcanzan firmeza sino después de que, comunicados a las 
Administraciones del Estado y autonómica, han transcurrido los plazos dentro de los cuales éstas pueden reaccionar frente a los mismos. Justamente a esta finalidad de impedir la firmeza de los actos locales sirven los deberes de comunicación e información y la facultad de solicitar ampliación de la información facilitada con suspensión del plazo legal para formalizar el conflicto, previstos en los artículos 56 y 64 LRBRL.

- El requerimiento contemplado en el artículo 65 LRBRL constituye (cuando se opta por formularlo) la reacción legalmente prevista frente al acto local reputado infractor del ordenamiento jurídico, es decir, el instrumento a través del cual se cuestiona formalmente la validez de dicho acto. Quiere decirse que, en la lógica y la economía de las relaciones interadministrativas de conflicto, equivale al recurso administrativo en las propias de las relaciones Administraciónadministrado (como, por demás, reconoce A. NIETO).

- El artículo 65.1 in fine LRBRL («... podrá requerirla, invocando expresamente el presente artículo, para que anule dicho acto o acuerdo»), y no sólo, por tanto, el artículo 215.3 ROFRJEL, determina la función y, por tanto, el efecto del requerimiento: pedir que se anule el acto o el acuerdo y, con ello, rehabilitar en el ente local destinatario la facultad de anulación. Porque si en la referida prescripción legal no está contenido el apoderamiento correspondiente, ¿qué sentido tendría la propia prescripción? Absurdo éste al que se abocaría, que de todo punto es rechazable.

Consecuentemente no existe ni vacío o lagunas legales algunos, de un lado, ni exceso reglamentario (el ROFRJEL se ha limitado a complementar y desarrollar, cumpliendo su función propia, lo contenido ya en la Ley), así como tampoco dificultad para insertar el supuesto en el régimen general de la reconsideración por la Administración de sus propios actos.

\subsubsection{El alcance de los requisitos formales impuestos al requeri- miento.}

La inclusión por la LRBRL de específicas "formalidades» en el régimen del requerimiento a dirigir a los entes locales ha llevado a la doctrina a plantearse los efectos del incumplimiento o del cumplimiento insuficiente o defectuoso de aquéllas. A mi juicio, los requisitos formales del requerimiento no son susceptibles de un 
tratamiento global homogéneo, pues no siendo todos ellos iguales debe discriminarse a la hora de la indagación y determinación de las consecuencias de su relativa o total inobservancia, debiendo distinguirse -en concreto- el plazo, la preceptiva invocación del artículo 65 LRBRL y la motivación, con indicación de la normariva vulnerada por el acto objeto del requerimiento.

- El plazo.

Es este un requisito general o, si se quiere, común a todos los mecanismos de la funcionalidad propia del requerimiento y que aquí no presenta ninguna especialidad. El juicio vale incluso para el cómpuro, aspecto en el que A. NiETo imputa a los artículos 65 LRBRL y 215 ROFRJEL falta de precisión. Pero es que la legislación de régimen local ni tenía, ni aún debía establecer reglas al respecto (ni siquiera reiterativas de las generales), toda vez que éstas tienen su sede en la LPA (arts. 56 a 61). Conforme a tales reglas los plazos se cuentan siempre a partir del día siguiente a aquél en que tenga lugar la notificación o publicación del acto de que se trate (art. 59 LPA). Esta y no otra debe ser la forma de computar el plazo que nos ocupa, por lo que la precisión «... a partir de la recepción de la comunicación ....) que realiza el precepto debe entenderse en un sentido congruente con la misma.

Tratándose de un requisito común, pero esencial, a todos los supuestos de formalización del cuestionamiento de la validez de un acto administrativo y siendo desde luego un plazo de caducidad, la inobservancia de aquél, es decir, el transcurso de éste tiene como consecuencia la imposibilidad jurídica del válido ejercicio de la facultad de requerimiento. Dicho de otro modo, el requerimiento deducido fuera de plazo carece de cualquier virtualidad en Derecho para trabar el conflicto regulado en el artículo 65 LRBRL y puede ser desconocido sin más por la Administración Local destinataria del mismo.

- La preceptiva invocación del artículo 65 LRBRL.

Es éste un requisito simplemente de orden dirigido al juego ordenado de los dos tipos básicos de conflicto (el de infracción sustantiva del ordenamiento y el de competencia), de suerte que, desde el principio, quede perfectamente delimitado el objeto del conflicto y la naturaleza de la pretensión que en él se deduce.

Consecuentemente, su incumplimiento puramente formal (no cita expresa del precepro) pero con determinación material del tipo de conflicto que se traba y deducción de pretensión congruente con el mismo no parece que deba enervar la producción por el 
requerimiento de sus efectos propios. En la medida en que, en tal hipótesis, se ha cumplido el fin de la norma, dicho requerimiento debe entenderse bien formulado. Sólo, pues, cuando de éste no se deduzca claramente su objeto o se formulen pretensiones sólo alcanzables por la vía de otra clase de conflicto podrá entenderse viciado por este motivo formal.

- La motivación, con indicación de la normativa vulnerada.

Es éste un requisito que, aludiendo al fondo de la cuestión objeto del conflicto, se refiere a la seriedad misma del requerimiento. La finalidad perseguida no es otra que el impedimento del uso torticero del sistema de control. Por tanto, la omisión de toda motivación constituye un defecto que impide desde luego el requerimiento de alcanzar sus efectos propios.

Como se ve, no existe una solución única, como sin embargo alguna doctrina postula sobre la base del principio pro actione y el artículo 114.2 LPA. Si para el requisito de la simple invocación del artículo 65 LRBRL tal posición doctrinal es compartible, no sucede lo mismo con el de la motivación, toda vez que la sanción del incumplimiento de este último debe ser a todas luces más rigurosa. En todo caso, la consecuencia conectada a la inobservancia de los requisitos estudiados nunca es irreparable desde el punto de vista de la operatividad del sistema de control, pues a la Administración incorrectamente requirente siempre le cabrá acudir a la vía contencioso-administrativa (recuérdese que en ese caso el plazo hábil es mayor: dos meses).

2.1.4 Los problemas que para el cómputo del plazo del requerimiento se deducen de la utilización de la facultad de pedir ampliación de la información sobre el acto o el acuerdo local

Presupuesto mismo del adecuado funcionamiento del régimen de impugnación de los actos locales es la sistemática comunicación de éstos a las Administraciones estatal y autonómica. De ahí el deber que establece el artículo 56 LRBRL; precepto, que para facilitar el cumplimiento de tal deber permite que aquella comunicación se realice mediante la remisión de «copia o, en su caso, extracto» de los actos y acuerdos locales. Justamente por ello puede suceder, y ello no será infrecuente, que la decisión acerca de si procede o no la impugnación de un acto sólo pueda adoptarse con fundamento a partir de una mayor información, de un mejor conocimiento del acto mismo y de sus antecedentes. Porque, en 
efecto, en caso de duda a la vista del simple extracto o de la mera copia del acto, esa debería ser la precaución lógica para evitar conflictos innecesarios o inútiles. Este es el fundamento, de todo punto plausible, de la previsión legal de la ampliación de la inicial y preceptiva información. Caso de solicitarse dicha ampliación, su efecto lógico es así el de la interrupción del transcurso del plazo legal para formular el requerimiento o, en su caso, la impugnación judicial. Justamente por ello la LRBRL establece ese efecto no en el capitulo de las relaciones interadministrativas, sino en el dedicado a la impugnación de los actos y acuerdos y el ejercicio de acciones.

Es cierto, sin embargo, que la petición formal de ampliación de la información puede dar luego a múltiples y distintos supuestos y que el ROFRJEL no ha producido en este orden de cosas una sustancial precisión de las soluciones a los mismos. Veamos los principales de tales supuestos:

a) La ampliación se solicita dentro de los quince días siguientes a la comunicación inicial del acto o acuerdo, produciéndose así la interrupción del plazo legal sin que éste se haya agotado, y el ente local responde dentro de los veinte días hábiles previstos en el artículo 64 LRBRL. En esta hipótesis ningún problema relevante se plantea. Suministrada la información complementaria pedida y reanudado el cómputo del plazo, el requerimiento deberá ser formulado inexcusablemente dentro del que aún restare, es decir, antes de su total expiración.

b) La ampliación se solicita igualmente dentro de los quince días siguientes a la comunicación del acto o acuerdo y se interrumpe el plazo legal, pero el ente local suministra la información ampliada interesada fuera del plazo de veinte días establecido a tal fin.

Aqui la conducta del ente local introduce un factor de inseguridad en todo equivalente al que deriva del silencio de la Administración en su relación con el ciudadano. El problema radica en que, una vez transcurrido el plazo de veinte días para evacuar el trámite de ampliación, no existe mecanismo legal que permita bien obligar al ente local a cumplir, bien despejar cualquier duda acerca de que de la opción por esperar el cumplimiento no se seguirá perjuicio alguno para la Administración estatal o autonómica actuante.

Sin perjuicio de volver sobre el problema en el supuesto siguiente, la efectiva ampliación de la información aún fuera de plazo reabre claramente el plazo para deducir el requerimiento, por lo que éste podrá deducirse mientras no transcurra la parte del mismo aún subsistente tras su interrupción por la petición de ampliación. 
c) Solicitada la ampliación en tiempo e interrumpido el plazo para formular el requerimiento, el ente local observa indefinidamente una actitud pasiva, sin dar respuesta alguna.

Frente a esta actitud del ente local, determinante de inseguridad en la respuesta a dar a la misma, cabe a la Administración requirente, en principio, una doble opción:

1. Esperar al cumplimiento por el ente local de su deber de suministrar la ampliación de la información, hipótesis idéntica a la anteriormente examinada, pero aboca a una situación sin otra salida que la del voluntario cumplimiento por el ente local a partir del momento en que han transcurrido ya no sólo los quince días hábiles para requerir en vía administrativa, sino también los dos meses para interponer recurso contencioso-administrativo (todo ello desde la comunicación inicial del acto o acuerdo de que se trate). Desde dicho momento, en efecto, el bloque LRBRL-ROFRJEL parece no ofrecer otra solución para la rehabilitación de la facultad de impugnación que la positiva y extemporánea respuesta local. Bastará, pues, a la entidad local con continuar observando una actitud pasiva o de silencio para bloquear definitivamente, en el caso, el control por parte de las Administraciones estatal o autonómica. Estas podrían ciertamente, en teoría, denunciar la mora en resolver sobre la petición de ampliación y deducir contra la denegación presunta de este recurso contencioso-administrativo en demanda de condena en resolver expresamente. Pero es claro que esta salida es en la praxis inidónea e impracticable.

2. Formular directamente recurso contencioso-administrativo en el plazo de dos meses a contar desde la comunicación inicial del acto o acuerdo.

Esta es la opción más correcta, por acomodarse mejor a lo dispuesto por la LRBRL. El artículo 65.3 in fine de la misma determina, en efecto y para el caso en que se hubiera optado por formular requerimiento previo, la interposición del recurso contencioso-administrativo «una vez transcurrido el plazo señalado en el requerimiento». El mero transcurso de éste (con independencia de si el ente local ha dado o no respuesta al requerimiento) provoca automáticamente el comienzo del cómputo del plazo legal (dos meses) para deducir aquel recurso, como precisa bien el artículo 215.4 ROFRJEL. Si esta es la solución legal para el supuesto posible de silencio frente al requerimiento, también debe serlo para el de pasividad ante la solicitud de ampliación de la información. Pues ambos se reconducen al de opción por el requerimiento administrativo previo, con la única diferencia de que la dificultad para el desarrollo, hasta su desenlace final, del conflicto (derivada 
de la actitud del ente local) surge en un momento anterior, impidiendo así que pueda entrar en juego la previsión legal por impracticabilidad de la formulación -debidamente motivada- del requerimiento. De este modo, no pudiendo jugar el automatismo legal en relación al plazo señalado en el requerimiento, éste ha de trasladarse al momento anterior, momento en el que el único plazo legalmente previsto es justamente el de la impugnación judicial directa (dos meses desde la comunicación inicial del acto o acuerdo). En definitiva, pues, la obstaculización al juego del requerimiento, imputable a la Administración local obliga a la reconversión del supuesto en una impugnación judicial directa; conversión para la que no existe dificultad, pues la suma de los plazos legales para el requerimiento (quince días hábiles) y para contestar a la petición de ampliación de la información (veinte días hábiles) es inferior al plazo legal para aquella impugnación. De adoptarse esta solución es claro que la inactividad de la Administración local ante la perición de ampliación de la información deja de plantear problemas de entidad.

d) La solicitud de ampliación de la información se deduce una vez transcurrido ya el plazo legal de quince días para formular el requerimiento.

El artículo 64 LRBRL no sujera la solicirud de ampliación de la información a un preciso plazo, lo que debe reconducirse al hecho de que este mecanismo constituye una pieza más de las que están al servicio del deber de facilitación recíproca de información sobre la propia gestión que incumbe a las Administraciones públicas conforme al artículo 55, c, LRBRL; deber que rige en cualquier tiempo. Ello no obstante, la referida solicitud guarda una específica conexión funcional con el sistema de conflictos interadministrativos, como luce en la ubicación sistemática del artículo 64 LRBRL y su efecto interruptor del decurso del plazo para formular el requerimiento administrativo previo. Así, pues, aun cuando desde la perspectiva genérica del deber de información deba afirmarse la posibilidad de deducir en cualquier momento la solicitud en cuestión y la obligación de la Administración local de atenderla, en su utilización al servicio del sistema de conflictos $y$, concretamente, del regulado en el artículo 65 LRBRL únicamente cabe su formulación dentro de los quince días hábiles siguientes a la comunicación primera del acto o acuerdo respecto del cual se precise mayor información, pues de producirse una vez transcurrido tal plazo, carecerá de toda virtualidad rehabilitadora del mismo. En otras palabras, como quiera que toda solicitud deducida fuera del indicado plazo no puede estar dirigida a preparar requerimiento 
alguno (pues la facultad para realizarlo ha caducado ya), la Administración local -aunque tenga el deber legal de dar una respuestapodrá, de hecho, optar entre darla o no, pues la inactividad o el silencio carecerán de toda sanción legal efectiva.

Siendo así que en la opción por la impugación judicial directa la solicitud de ampliación de la información, de deducirse, carece de todo efecto interruptor del plazo legal para la interposición del pertinente recurso contencioso-administrativo, es claro que para ser operativa deberá realizarse tempranamente, a los efectos de que pueda transcurrir el plazo de contestación a la misma (veinte días hábiles) sin que se haya agotado aún aquel otro. También es claro aquí que una solicitud de ampliación de la información deducida una vez caducada la posibilidad de acceso a la jurisdicción contencioso-administrativa carece de cualquier eficacia en orden a reabrir dicha posibilidad.

Además de todo lo hasta aquí razonado, la ampliación de la información suscita la cuestión acerca de si sólo es posible deducir la correspondiente solicitud una vez o cabe reiterar ésta. La importancia práctica de tal cuestión se circunscribe, por obvias razones, al supuesto de requerimiento administrativo previo; supuesto en el que, en su caso, podrían darse sucesivas interrupciones del plazo legal para formular este último. La respuesta parece que debe ser la de la no reiterabilidad de la solicitud, toda vez que es la más conforme con el sentido y la economía institucionales del conflicto a cuyo desarrollo y desenlace adecuados sirve. De otro lado, es la que dispensa una mayor garantía a la Administración local objeto de control; perspectiva ésta en modo alguno secundaria. A todo ello se añade que la reiteración únicamente podría tener una finalidad dilatoria incompatible con la exigencia de la pronta clarificación del conflicto, toda vez que las Administraciones del Estado y autonómica cuentan con mecanismos complementarios suficientes para hacer efectiva la primera y única petición; en concreto la demanda de exhibición de expedientes y de emisión de informes, conforme a lo prevenido con carácter más general en el artículo 56.2 LRBRL.

\subsubsection{La relación entre el requerimiento previo y la impugnación judicial}

La utilización por la Administrtación estatal o, en su caso, la autonómica del requerimiento administrativo constituye una opción legítima, de la cual no puede seguirse perjuicio en orden a la posibilidad de sustanciar el conflicto, en último término, en sede judicial. De ahí que el número 3 del artículo 65 LRBRL no admita 
más que una interpretación: la impugnación judicial se ha de producir, bien directamente dentro de los dos meses siguientes a la comunicación inicial del acto o acuerdo local, bien (hipótesis que aquí interesa) dentro de los dos meses siguientes al transcurso del plazo concedido en el requerimiento administrativo correspondiente a la Administración local para, en su caso, anular su propio acto o acuerdo, cuando efectivamente se haya optado por formular previamente dicho requerimiento. Ello significa que éste no constituye una diligencia preliminar (al proceso judicial) preceptiva en todo caso, pero sí un mecanismo potestativo que, de emplearse, representa una diligencia preliminar de necesaria cumplimentación antes del acceso a la vía judicial. Es plenamente consecuente, pues, que el requerimiento administrativo demore el recurso contenciosoadministrativo. El desarrollo legal que ha hecho el artículo 215.4 ROFRJEL resulta ser, así, rigurosamente correcto.

\subsubsection{La atención parcial del requerimiento}

Es perfectamente posible que la entidad local a la que se haya formulado un requerimiento administrativo para la anulación de un acto o acuerdo decida no proceder ni a desatender simplemente, ni a atender en todo dicho requerimiento, sino más matizadamente -en razón a la ponderación de los argumentos aducidos en el requerimiento- a atenderlo en parte y rechazarlo en el resto. Semejante supuesto arroja el no despreciable interrogante de si frente a la respuesta local sólo cabe a la Administración requirente decidir entre la aceptación de la misma (dando por resuelto el conflicto) o la impugnación judicial del acto o acuerdo inicial y de la respuesta al requerimiento, en la parte en que las pretensiones de aquélla no se hayan visto satisfechas en la vía administrativa 0 , por el contrario, le es factible -teniendo en cuenta que la respuesta al requerimiento introduce un factor nuevo- una tercera opción intermedia: la de formular un nuevo requerimiento. La función que despliega el requerimiento previo (paralela, en el sistema de conflictos interadministrativos, a la que es propia del recurso administrativo en el sistema de conflictos Administración-administrados) desactiva el único argumento que cabria aducir en favor de tal tercera opción, el de que la respuesta local constituye un nuevo acto que replantea los términos del conflicto. Pues si tal argumento hubiera de tenerse en cuenta, habría de serlo también en el desenlace del segundo y sucesivos (posibles) requerimientos, sin que fuera imaginable un criterio válido para poner fin al proceso de alimentación sucesiva así puesto en marcha. 
En la medida en que el requerimiento constituye sustantivamente un mecanismo de composición administrativa del conflicto y procesalmente, una vez formulado, un requisito o diligencia de obligado cumplimiento para la judicialización de dicho conflicto, la aceptación sólo parcial de aquél no rehabilita su utilización, por lo que en tal caso a la Administración requirente únicamente se le ofrecen las dos opciones ya indicadas: o darse por satisfecha con lo conseguido o, por el contrario, proceder a la impugnación judicial de las decisiones locales que continúen reputándose ilegales.

\subsubsection{El juego de la medida cautelar de suspensión en la fase judicial del conflicto}

El artículo 65 LRBRL se limita a disponer la judicialización del conflicto que regula (tanto la directa como la demorada por el requerimiento previo), sin incidir para nada en la regulación del procedimiento una vez que se ha alcanzado el momento de dicha judicialización. Consecuentemente, el procedimiento a seguir para la sustanciación del conflicto en sede judicial no puede ser y no es otro que el regulado como ordinario para el recurso contenciosoadministrativo en la LJCA. Esta conclusión vale también para el procedimiento incidental para la adopción de la medida cautelar de la suspensión. Si la LRBRL nada ha dicho a este respecto en su artículo 65, diciéndolo -por contra- en su artículo 66 para el conflicto competencial, ninguna duda ofrece que el legislador no ha querido introducir en aquél innovación alguna.

En el conflicto que nos ocupa las Administraciones dilucidan, pues, ya en sede judicial, el litigio que las enfrenta conforme en todo a las reglas del procedimiento ordinario del recurso contencioso-administrativo, por más que en el objeto de éste no se contrapongan un interés público y un interés privado, sino dos intereses públicos. La alteración provisional, mientras se sustancia y decide el proceso, de la situación creada por el acto o acuerdo local únicamente resulta posible solicitando y obteniendo del Juez, en vía incidental y conforme al artículo 122.2 LJLA, la suspensión de dicho acto o acuerdo.

\subsection{EL CONFLICTO Y LA IMPUGNACIÓN DEL ARTíCULO 66 LRBRL (ART. 216 ROFRJEL)}

El regulado en el artículo 66 LRBRL es un conflicto. específico, circunscrito en su objeto a los supuestos en que la atención de un ente local (determinados actos o acuerdos del mismo) suponga un menoscabo de competencia o competencias legalmente atribuidas 
a la Administración del Estado o a la de la correspondiente Comunidad Autónoma, una interferencia en el ejercicio de alguna de las competencias de éstas o represente, incluso sin necesidad de aquel menoscabo o esta interferencia, una extralimitación de la esfera competencial local. La justificación de su configuración legal independiente radica en la cualificación de la transgresión que constituye su objeto y la necesidad de su corrección a cravés de un mecanismo específico, ajustado a las características de aquella transgresión y su potencialidad perturbadora del orden interno del complejo y plural ordenamiento del Estado en su conjunto. Los elementos diferenciadores de este conflicto respecto al previamente regulado en el artículo 65 LRBRL son dos: la completa judicialización, toda vez que frente al acto local calificado de transgresor del ordenado juego del sistema competencial no cabe sino la impugnación judicial, si bien en un plazo reducido (respecto al general establecido para la interposición del recurso contenciosoadministrativo) y coincidiendo con el conferido en el conflicto previsto en el referido artículo 65 para la formulación, en su caso, de requerimiento administrativo previo, es decir, quince días hábiles, de un lado; y la articulación de reglas especiales para el arreglo provisional o cautelar de la contradicción de intereses subyacente al conflicto. En lo demás éste se sustancia por el procedimiento ordinario del recurso contencioso-administrativo.

También en este caso el supuesto legal plantea, además de las cuestiones generales en su momento abordadas, algunas peculiares, que se pasan a examinar.

\subsection{1 ¿Es posible la formulación de requerimiento administrativo previo, con demora de la judicialización del conflicro?}

Algún autor [A. NIETo] sostiene una respuesta positiva a este interrogante, basándola en la remisión que el párrafo $1 .^{\circ}$ in fine del artículo 66 LRBRL hace «al plazo señalado por el número 2 del artículo anterior" (que es el de la formulación del requerimiento administrativo previo en el contexto del conflicto regulado por el artículo 65 LRBRL).

Como ya se ha adelantado, esta tesis no parece correcta. La remisión es sólo en cuanto al plazo, por lo que no puede extenderse a la facultad misma de requerimiento. Además, y esto es decisivo, la acumulación sucesiva de este último y del recurso judicial es sencillamente imposible porque -ateniéndose justamente a la indicada remisión- el plazo para interponer el recurso contenciosoadministrativo comienza a correr precisamente a partir de la comunicación inicial por el ente local del acto o acuerdo correspon- 
diente. De esta suerte, ambos plazos (el del requerimiento supuestamente posible y el del recurso judicial) serían idénticos y transcurririan paralelamente, sin que existiera la posibilidad de que el planteamiento del requerimiento enervara el decurso del plazo del recurso, al no contener el artículo 66 LRBRL parecida previsión a la incluida en el número 3 del artículo anterior de la misma.

La exclusión en este tipo de conflicto del requerimiento previo no significa que la Administración del Estado o autonómica no pueda, una vez recibida la copia del pertinente acto o acuerdo, solicitar ampliación de la información relativa al mismo e interrumpir, así, el plazo para formalizar la impugnación judicial. El artículo 64 LRBRL dispone esta interrupción con carácter general para el plazo previsto en el número 2 del artículo 65 de la misma Ley, por lo que si el artículo 66 , párrafo $1 .^{\circ}$, igualmente de ésta remite al plazo señalado en dicho precepto, es claro que debe regir para el conflicto regulado en él la referida interrupción, en la medida en que ésta forma parte del régimen propio del repetido plazo. Consecuentemente, es integramente trasladable aquí todo lo dicho en torno a la solicitud de ampliación de la información y su efecto interruptor del decurso del plazo para reaccionar frente al acto o acuerdo local con ocasión del análisis del conflicto regulado en el artículo 65 LRBRL.

\subsubsection{Los requisitos formales de la impugnación: Su alcance}

También en este conflicto la LRBRL sujeta la impugnación (ahora judicial) a unos específicos requisitos, que suponen, por tanto, una modulación del régimen general del proceso contencioso-administrativo establecido en la LJCA; precisión ésta con la que debe completarse la caracterización general del conflicto que en su momento se avanzó.

Los requisitos son dos: la precisión de la lesión o, en su caso, la extralimitación competenciales que motiva la impugnación y la indicación de las normas legales vulneradas en que ésta se funda. El uno se refiere, pues, a la actuación del ente local, mientras que el otro mira a los mandatos-habilitaciones competenciales de la Administración impugnante. Sin perjuicio de su diferenciación, no son en último término, sin embargo, más que dos perspectivas de una sola exigencia: la de motivación de la impugnación. A ésta no le basta, para estar fundada, con la inexistencia de un fundamento competencial expreso en la acción local, siéndole precisa, además, la existencia de una atribución competencial clara del objeto de dicha acción en favor de la Administración impugnante. Sólo cuando concurran ambos aspectos quedará bien trabado el con- 
flicto, pues únicamente entonces se dará desde luego una lesión de la competencia de la Administración del Estado o autonómica o se habrá producido una verdadera extralimitación competencial por parte de la Administración Local en el sentido del artículo 66 LRBRL.

Puede hablarse, pues, de un sólo requisito alusivo a la motivación de la impugnación. Como quiera que éste opera no sobre una diligencia preliminar al proceso contencioso-administrativo (cual sucede con los requisitos impuestos al requerimiento administrativo en el conflicto del artículo 65 LRBRL), sino sobre el propio proceso, la principal cuestión que suscita es la del momento 0 , si se quiere, el trámite en que deba cumplirse. Los trámites a tener en cuenta son los de interposición del recurso y de formulación de la demanda, pues el artículo 66 LRBRL remite sin duda al procedimiento ordinario y aquí no se está en el supuesto de impugnación por la propia Administración de un acto por ella misma producido (recurso de lesividad). Dada la trascendencia que el propio precepto legal concede al primer trámite de la impugnación y la expresión «presentación de la impugnación» que utiliza para identificarlo, es en el de interposición del recurso donde la motivación requerida por la Ley debe explicitarse. Sólo así podrá el Juez estar en condiciones de comprobar si el conflicto está correctamente entablado y procede adoptar, en su caso, medidas cautelares. De esta forma, el requisito específico de motivación debe entenderse como un añadido por la legislación de régimen local a los que el artículo 57 LJCA prescribe con carácter general. Ello significa que, en caso de incumplimiento o de cumplimiento defectuoso, cabe la subsanación en los términos del número 3 de este último artículo.

\subsubsection{La suspensión provisional o cautelar del acto o acuerdo objeto del conflicto}

El elemento sin duda más novedoso del artículo 66 LRBRL es el de establecimiento de una regulación peculiar para el arreglo provisional o cautelar por el Juez, pendiente el proceso principal, de la colisión de intereses públicos (supralocales y locales) subyacente al conflicto entre las Administraciones.

La justificación de esta regulación singular, excepcionadora de la de carácter general contenida en el artículo 122 LJCA, no parece que pueda ser cuestionada. En cuanto al fondo, su necesidad era y es evidente. El régimen general de la medida judicial de suspensión no sólo es muy parco, sino que responde al modelo de conflicto o contencioso propio de la relación Administraciónadministrado; es decir, descansa en una contraposición de dos 
intereses de naturaleza idealmente distinta: el interés público y el interés privado. Su economía responde, pues, a ese modelo y resulta, por tanto, inadecuada a la tensión y contraposición de intereses públicos y sólo entre éstos que es propia del conflicto interadministrativo de que aquí se trata.

Ciertamente puede criticarse la fragmentación del régimen de la medida judicial cautelar de suspensión a causa de la proliferación de regulaciones específicas o peculiares $y$, por tanto, lamentarse que la LRBRL haya dado un paso más en esa línea. Pero ni el proceso mismo de progresiva diversificación de aquel régimen puede imputarse a ésta, ni parece posible pretender frenarlo y recuperar un orden y una claridad en dicho régimen sin una reforma a fondo del sistema contencioso-administrativo. También puede ser objeto de crítica la opción en favor de una regulación en el marco de la legislación de régimen local, desechando la de modificación concreta, a este fin y desde dicha legislación, de la reguladora de la Jurisdicción contencioso-administrativa. Pero tampoco aquí la LRBRL ha sido pionera y su opción puede presentarse como igualmente $e$, incluso, más respetuosa con aquella normativa procesal entretanto no tiene lugar su tan necesaria renovación.

Los elementos más sobresalientes de la suspensión cautelar peculiar del conflicto analizado son los siguientes:

a) No es automática, debiendo ser solicitada su adopción por el Juez de forma motivada.

Desde el punto de vista procesal puede deducirse ya en el mismo momento de la upresentación de la impugnación», es decir, de la interposición del recurso contencioso-administrativo. De hacerse así, deberá abrirse inmediatamente el correspondiente incidente de suspensión. Tal posibilidad, sin embargo, no significa que la correspondiente petición, habiéndose omitido en la interposición, no pueda deducirse "en cualquier estado del proceso», conforme autoriza el artículo 123.1 LJCA. El artículo 65 LRBRL -norma especial- se limita a contemplar aquella posibilidad, sin contener prescripción alguna otra y desde luego ninguna prohibitiva del planteamiento de la cuestión de un momento ulterior o determinante de la caducidad de la facultad para hacerlo de no haberse ejercitado ésta en el trámite de interposición. Consecuentemente nada obsta a la aplicación del artículo 123.1 LJCA, en calidad de norma general.

b) La motivación ha de centrarse precisa y únicamente en la colisión de intereses públicos presente en el conflicto y consistir en razonar suficientemente que la integridad y la efectividad de aquellos a los que sirve la Administración impugnante demandan 
que no se produzca la ejecución del acto o acuerdo impugnado, es decir, no se realice el interés local hasta tanto no se decide sobre el fondo del conflicto.

No basta con que la petición sea motivada, es preciso que su fundamentación sea convincente, es decir, que pueda ser considerada "fundada" por el Juez.

c) La solicitud de suspensión, caso de deducirse precisamente en la interposición del recurso contencioso-administrativo, obliga al Juez a pronunciarse sin mayor dilación, ni tramitación contradictoria alguna, en el primer trámite subsiguiente.

Es quizá este el punto donde la regulación examinada introduce una mayor dosis de innovación para con respecto al régimen general de la suspensión, al suprimirse -al menos para el primer pronunciamiento sobre la suspensión- todo elemento de contradicción. Desde el punto de vista de los principios (fundamentalmente desde el derecho de defensa) nada puede objetarse a esta solución, dado el alcance puramente cautelar y provisional de la medida que se deriva de la estimación de la solicitud y la posibilidad que expresamente se concede a la Administración local -una vez que ha venido en conocimiento de la medida- de instar su alzamiento - modificación, lo cual es posible sin mayores problemas en la medida en que la suspensión no causa estado ni deviene decisión firme.

La exclusión, en un primer momento, de toda contradicción encuentra su razón de ser justamente en la opción legal en favor de la judicialización del conflicto. Desprovistas las Administraciones del Estado y de las Comunidades Aurónomas de todo mecanismo para hacer efectivo, siquiera sea en el plano de la eficacia de los actos y a título meramente provisional, el resultado de su control sobre las entidades locales en punto al respecto por éstas de los límites de su ámbito competencial, la contrapartida había de ser el arbitrio de una fórmula ágil y operativa para que dicha efectividad pudiera alcanzarse inmediatamente en sede judicial.

Dicho esto, conviene advertir dos extremos importantes. En primer término, que la valoración a realizar por el Juez a los efectos de resolver sobre la solicitud no es plena, en cuanto limitada al fundamento mismo de la petición, sin extenderse a una total ponderación de los intereses en juego. Lo que el Juez ha de decidir por de pronto es sólo si puede y debe estimar o no fundada dicha solicitud. Y es lógico que así sea, pues su decisión ha de producirse sin contradicción, es decir, sin contar con los elementos de juicio que sobre las exigencias del interés público que sirve le podría proporcionar la Administración local demandada. En esta limitación del poder cautelar del Juez se traduce la contrapartida a la 
judicialización del conflicto a que acaba de aludirse. Formulado el juicio sobre el fundamento de la solicitud $y$ caso de ser éste positivo, el Juez está obligado, en segundo lugar, a acordar la suspensión pedida. El artículo 65 , párrafo $2 .^{\circ}$ LRBRL no deja lugar a dudas al respecto. "... el Tribunal, si la estima fundada (el precepto se refiere a la solicitud), acordará dicha suspensión...». Por tanto, el Juez únicamente podrá denegar la suspensión en el supuesto de desestimación previa, por infundada, de la correspondiente petición.

Este régimen excepcional de la suspensión (al menos en el primer pronunciamiento sobre la misma), en el que luce desde luego una inicial desigualdad procesal de las partes en favor de la Administración demandante, suscita la no despreciable cuestión de si rige sólo en los términos estrictos en que aparece establecido, es decir, para cuando la correspondiente petición se deduce en la interposición del recurso contencioso-administrativo o también es aplicable a las peticiones formuladas después a lo largo del proceso.

Es indudable que el favorecimiento de la posición de la Administración demandante $(y$, a su través, de los intereses públicos a los que la misma sirve) encuentra su razón de ser en la exigencia del restablecimiento inmediato -en el plano que es propio a las medidas cautelares- del "orden» de los intereses públicos, es decir, de la prevalencia -como regla general- de los propios de las colectividades mayores sobre los de las menores. Ahora bien, tal exigencia se presentará con mayor o menor intensidad, en unos $u$ otros términos en función de las circunstancias del caso, es decir, del grado en el que en el mismo se vea comprometido en efecto el interés público que, en principio, es prevalente $y$, por reflejo, el propio orden general de los intereses públicos. De ahi que el artículo 65 , párrafo $2 .^{\circ}$ LRBRL no obligue a la Administración demandante a solicitar la suspensión, pero conecte a la apreciación de la pertinencia de ésta y a su efectiva solicitud desde la misma formalización del conflicto el régimen excepcional estudiado. Este último aparece, así, vinculado a la valoración que de la situación concreta haga en cada caso la Administración demandante en el momento de interponer el recurso. Quiere decirse que el artículo 65, párrafo $2 .^{\circ}$ LRBRL debe interpretarse en el sentido de que el régimen excepcional de suspensión que.contempla sólo rige cuando ésta se haya solicitado en el escrito de interposición. Cualquier petición deducida en otro-estado ulterior del proceso deberá, pues, tramitarse y decidirse conforme al régimen general de la LJCA. Obviamente la remisión a este último vale para los elementos singulares del régimen especial analizado (tramitación 
sin contradicción y limitación del poder de valoración del Juez), no así para las reglas de fondo sobre la ponderación de los intereses en presencia. Téngase en cuenta que en el régimen general el supuesto de colisión entre intereses públicos no está previsto, por lo que esa laguna no puede integrarse sino a partir justamente del artículo 65 LRBRL.

d) Acordada la suspensión, la entidad local demandada puede, en cualquier momento a lo largo del proceso, interesar la modificación o el alzamiento de la misma.

A partir de este momento, el incidente se vuelve contradictorio, de suerte que cualquier decisión judicial sólo puede pronunciarse oyendo previamente a la otra parte, en este caso la Administración demandante. Dada la óptica de la regulación legal -el conflicto entre dos Administraciones-, los derechos e intereses de terceros destinatarios eventuales del acto o el acuerdo que haya dado lugar al conflicto no aparecen considerados. Pero es claro que aquí, al igual que en el proceso principal, pueden comparecer dichos terceros como parte. El artículo 24 de la Constitución no permite solución otra alguna. $Y$ estos terceros, en la medida en que la suspensión decretada les perjudique, podrán tanto deducir peticiones de modificación o alzamiento paralelas a la que deduzca, en su caso, la entidad local, como alegar cuanto convenga a sus derechos o intereses legítimos (siendo preceptiva, desde luego, su audiencia).

Pero al mismo tiempo, la contradicción devuelve al Juez la plenitud de su poder, que ahora se extiende a la total ponderación de las exigencias recíprocas de los intereses públicos en conflicto. La regla de fondo a la que esa ponderación ha de atenerse, la establece el propio artículo 65 , párrafo $2{ }^{\circ}$ LRBRL: el interés general o el comunitario prevalecen sobre el local, salvo que en el caso concreto se acredite que esa prevalencia hecha valer provisionalmente produce $o$ va a producir un perjuicio al interés local no justificable desde las exigencias de aquel interés general o comunitario. La modificación o el alzamiento de la suspensión por el Juez depende de que se razone ante él convincentemente la realidad del perjuicio en los términos indicados.

Lo importante es, sin duda, la capacidad de valoración que se reconoce al Juez y que se traduce en la posibilidad que tiene de modular -en función de dicha valoración- el alcance de su decisión. Esta podrá consistir en la confirmación de la suspensión, en su modificación (alzándola sólo en parte) o, finalmente, en su alzamiento total. 


\subsection{EL CONFLICTO Y LA IMPUGNACIÓN DEL ARTÍCULO 67 LRBRL (ART. 217 ROFRJEL)}

Atendida la redacción misma del precepto legal (que el ROFRJEL se limita a reproducir) es claro que pretende acotar el supuesto de conflicto más enérgico que pueda resultar de la adopción por una entidad local de actos o acuerdos concretos. Se trata de un supuesto a todas luces excepcional y extraordinario, tanto que -por contraposición a los conflictos regulados en los dos artículos inmediatamente anteriores de la Ley-aquí el bien lesionado por la acción local es sólo de carácter nacional, por lo que únicamente la Administración del Estado y la local pueden ser partes en el mismo. El objeto se acota con la expresión «actos o acuerdos que atenten gravemente al interés general de España»; expresión que, dada su abstracción y su consecuente imprecisión, es objeto de crítica por parte de la doctrina (G. Fernández farreres J. Bermejo A. Nieto). Las deficiencias de la expresión legal para delimitar jurídicamente con suficiente precisión la realidad a la que se refiere son bien evidentes: de un lado, si ya el concepto «interés general» es indeterminado, su cualificación como "de España» incrementa notablemente la indeterminación; de otro lado, la exigencia de que la lesión de tal interés sea "grave» introduce un factor de por lo menos difícil valoración.

Sin perjuicio del reconocimiento de la notable dificultad que para la aplicación del precepto legal que lo regula (así como para el control judicial de dicha aplicación) resulta de la construcción jurídica del objeto del conflicto con conceptos enormemente indeterminados, no puede compartirse la opinión (A. NIETO) de que el referido control judicial o bien ha de realizarse sobre la verificación de la conformidad a Derecho del acto o acuerdo local (en la hipótesis de que éste, además de suponer un atentado grave al interés general de España, infrinja el ordenamiento jurídico) o bien ha de consistir en un enjuiciamiento del mismo que, para ser jurídico, ha de refugiarse en el parámetro constitucional (en la hipótesis de que el acto o acuerdo atente gravemente al interés general de España sin por ello infringir directamente precepto alguno de la legalidad ordinaria). Semejante descomposición del supuesto legal en dos alternativas descansa en un presupuesto no demostrado: el de que dicho supuesto legal carece de sustantividad propia y capaz de regir la resolución administrativa y judicial del conflicto.

Se insiste nuevamente, el supuesto definido por la Ley será indeterminado, pero de ello sólo se sigue una específica y superior 
dificultad del proceso jurídico para su aplicación y del controi de la misma, en modo alguno la imposibilidad de éstos, desde la que se intente justificar una no confesada ureconversión» de la norma gracias a la traslación del criterio rector a una ilegalidad o una inconstitucionalidad material calificable de atentado grave al interés de España. Es claro que el artículo 67 LRBRL ha querido definir la irregularidad máxima de entre los previstos por el sistema de conflictos interadministrativos (desencadenante, por ello, de las respuestas más enérgicas que contempla la Ley) justamente como atentado para el interés general de España, por lo que este último integra la única regla determinante para entablar $y$ resolver el conflicto correspondiente.

Si se tiene en cuenta que el artículo 67 LRBRL no es sino una "traducción" al ámbito local de lo dispuesto, para las relaciones Estado stricto sensu-Comunidades Autónomas, en el artículo 155 de la Constitución, el cual -a su vez-constituye el trasunto en nuestro sistema del mecanismo de la coacción federal, se obtiene cuando menos el resultdo de que el supuesto examinado tiene carácter excepcional y extraordinario, lo que permite circunscribir su concurrencia a situaciones verdaderamente extremas, para cuya satisfactoria resolución no basten, con toda evidencia, las posibilidades de reacción que ofrecen los artículos 65 a 67 LRBRL. No obstante, la dificultad para la determinación jurídica del supuesto subsiste, como es obvio, pero es bien evidente que la misma no es solventable en un plano abstracto $y$ general, debiendo quedar remitida su resolución a cada caso concreto.

El conflicto suscita aún algunas otras cuestiones $y$, entre ellas $y$ como más importantes, las que pasan a analizarse.

\subsubsection{La estructura del conflicto y sus elementos}

El conflicto aparece claramente dividido en dos fases, gubernativa o administrativa una, judicial la otra. Esta división no afecta sólo al desarrollo mismo del conflicto, pues persigue más bien su descomposición en dos partes diferenciadas con contenidos propios y distintos, si bien enlazadas ambas por un objeto común: el atentado grave al interés general de España.

Conforme a su diseño legal, la fase administrativa no pretende alcanzar por sí misma el arreglo definitivo de la cuestión de fondo (lo que requeriría la eliminación del mundo jurídico del acto o acuerdo local atentatorio gravemente al interés general de España). Persigue únicamente y como máximo conseguir un reconocimiento por la entidad local (en concreto, a través de su presidente) de que se ha producido tal atentado grave a dicho interés y la consecuente 
adopción de medidas por parte de dicho presidente que, atendiendo al requerimiento que le ha sido formulado, eviten ta persistencia del atentado entre tanto pueda procederse a la anulación del acto o acuerdo local. El hecho de que el destinatario del requerimiento gubernativo sea siempre el presidente de la entidad, es decir, su órgano ejecutivo (el que tiene que asegurar la ejecución de todos los actos y acuerdos de aquélla; función implícita en la regulación legal de las competencias del Alcalde -art. 21, a, LRBRL-y que por ello ha precisado el Texto Refundido en su artículo 24, $g$ y explícita en la de las competencias del Presidente de la Diputación -art. 34.1, j- LRBRL), con independencia de cual haya sido el órgano que adoptó el acuerdo o dictó el acto, revela que esta es la única interpretación correcta del contenido y alcance del conflicto en su fase administrativa. Al desconocimiento de los límites de esta fase debe reconducirse el planteamiento por algún autor de falsos problemas en la interpretación del precepto legal.

Lo dicho no significa que en la hipótesis de la coincidencia entre órgano requerido y órgano competente para anular el acto o acuerdo controvertido por haber emanado éste de él, no sea posible que, en el marco de esta fase administrativa del conflicto y con motivo de la respuesta al requerimiento, se produzca una decisión anulatoria que resuelva definitivamente el conflicto. Supone tan sólo que éste no es el resultado normal y necesario, previsto como tal, con carácter general, por la norma legal. Justamente porque la fase administrativa se agota en evitar la consumación, en su caso, la persistencia en el plano de los hechos, de la realidad, del atentado objeto del conflicto, la reacción ante la no atención del requerimiento practicado se circunscribe -por lo que respecta a su incidencia en la acción local- a dicho plano, toda vez que únicamente puede consistir en la suspensión del acto o acuerdo local (sin alcanzar, pues, a su validez). Cierto que el Delegado del Gobierno puede, además, adoptar medidas dirigidas a la protección del interés general, pero tales medidas, sobre ser exclusivas de la Administración del Estado y dejar subsistente jurídicamente el acto o acuerdo local controvertido, se mueven en el mismo plano que la suspensión.

Por contra, la fase judicial versa precisamente sobre la validez del acto o acuerdo local suspendido previamente, toda vez que en ella se impugna tal acto o acuerdo. Pero por lo mismo ése es su único contenido, no comprendiendo las medidas adoptadas en la fase administrativa, concretamente las que lo hayan sido por el Delegado del Gobierno. La redacción del artículo 67 LRBRL es clara 
y no deja lugar a dudas acerca de su interpretación. La consecuencia obligada es que en el proceso abierto con la impugnación formulada por el Delegado del Gobierno nada puede resolverse, ni siquiera cautelarmente, sobre las referidas medidas, sin perjuicio de que la entidad local las pueda impugnar, a su vez, de forma separada e independiente. Quiere decirse que la suspensión y las restantes medidas decididas por dicho Delegado del Gobierno subsistirán a lo largo de toda la fase judicial y hasta que recaiga Sentencia firme, a salvo lo que sobre las mismas pueda disponerse por el Juez contencioso-administrativo con ocasión de su impugnación por la entidad local, si ésta se produjere.

Justamente en esta especifica estructura del conflicto y en las consecuencias que de la misma resultan radica la mayor energía de que el legislador de régimen local ha querido dotar a la reacción frente a la irregular conducta de la Administración local en razón a la mayor gravedad que ésta presenta en el supuesto contemplado.

\subsubsection{La fase administrativa del conflicto; aspectos más proble- máticos}

El conflicto se formaliza inicialmente siempre por medio de un requerimiento que únicamente puede formular el Delegado del Gobierno en la correspondiente Comunidad Autónoma y tiene como destinatario necesario el presidente de la entidad local a la que se reproche el atentado grave al interés general de España.

El precepto legal no fija plazo alguno en el que deba formularse el requerimiento. De ello no parece que pueda seguirse, sin embargo, la posibilidad de que quepa realizarlo en cualquier tiempo, toda vez que ello repugnaría a la seguridad jurídica. La naturaleza misma del conflicto y la consecuente regulación que de su planteamiento, desarrollo y desenlace se hace, claramente dirigida a una resolución expeditiva y rápida, siquiera sea provisional y en el terreno de los hechos, obliga a entender que el requerimiento debe producirse de forma inmediata, en términos de pronta reacción frente al atentado al interés general de España que la adopción del acto o acuerdo local provoca. De ahí que una interpretación sistemática avale la conclusión de que el requerimiento en cuestión no podría válidamente deducirse, en principio y como regla general, más allá de los quince días siguientes a la comunicación del acto o acuerdo en cuestión. En efecto, si la LRBRL ha querido limitar a dicho tiempo el hábil para la primera reacción por parte de las Administraciones estatal o autonómica en el caso de los conflictos menos graves que el ahora considerado, forzoso resulta derivar de ello que el plazo en que tal primera reacción debe tener lugar en 
este último no podrá ser superior. Pues ha de tenerse en cuenta la importancia del bien jurídico de cuya protección se trata -el interés general de España- y el dato de que si el supuesto legal es de por sí -dada su indeterminación- de difícil concreción, mucho más difícil será, por no decir imposible, la justificación de su concurrencia para fundamentar un requerimiento cuando ya ha transcurrido el tiempo hábil para actuar frente a una simple ilegalidad o una transgresión competencial. Así, pues, aun no siendo posible hablar aquí -por falta de precisión legal sobre el plazo- de extemporaneidad en el requerimiento, cabe retener que todo aquel que se practique después de transcurridos quince días hábiles desde la comunicación del acto o acuerdo local deberá justificar satisfactoriamente la dilación con que se produce como condición misma para su viabilidad.

Tampoco fija el artículo 67 LRBRL el plazo en que la entidad local deba dar una respuesta al requerimiento; plazo que se supone habrá de concretarse de cada vez por éste, a cuyo efecto ni siquiera se establece criterio o regla algunos conforme a los que deba procederse. Es claro que el plazo habrá de ser razonable y adecuado, teniendo en cuenta el objeto del conflicto $(y$, por tanto, la exigencia del más pronto restablecimiento de la efectividad del interés general de España) y la actuación demandada de la entidad local. Desde el primer punto de vista el plazo ha de ser lo más breve posible. Desde el segundo, dicho plazo ha de tener la duración suficiente como para permitir la correcta formación del juicio y la voluntad correspondiente en el órgano local requerido. A este respecto debe recordarse aquí lo ya razonado acerca del alcance de esta fase del conflicto: aun cuando la Administración requirente cuestione indudablemente la validez del acto o acuerdo local y pretenda, en último término, su anulación, no necesariamente debe obtener en la respuesta a su requerimiento, si éste es atendido, satisfacción definitiva a dicha pretensión, bastando con que aquélla suponga la suspensión de la ejecución del acto o acuerdo o la enervación en cualquier otra forma de su eficacia hasta tanto la anulación efectivamente tiene lugar. Esta consideración repercute como es obvio sobre la valoración de la duración del plazo a otorgar a la entidad local. Con carácter general puede decirse que éste no debería ser inferior al que ha mediado entre la comunicación del acuerdo o acto y la formulación del requerimiento, ni en cualquier caso a cinco días lla mitad a que puede reducirse, por razón de urgencia, el plazo mínimo de audiencia o alegaciones: artículo 91.1, en relacion con el 58.1 LPA).

El mero transcurso del plazo concedido en el requerimiento sin que la entidad local haya dado respuesta al mismo habilita sin más 
al Delegado del Gobierno para adoptar las medidas previstas en el precepto legal: la suspensión del acto o acuerdo local al que se impute el atentado grave al interés general de España y todas aquellas disposiciones pertinentes para asegurar la protección de este interés. El tenor literal del artículo 65 LRBRL permite indudablemente al Delegado del Gobierno, ante la pasividad o el silencio de la entidad local, esperar más allá del referido plazo una respuesta expresa de ésta, pues ni el deber de ulterior acción por parte de dicho Delegado surge sino «en el caso de no ser atendido» el requerimiento, ni el plazo para impugnar judicialmente empieza a correr sino a partir de la suspensión del acto o acuerdo local, es decir, de aquella acción gubernativa. Es cierto que, en tal caso, ningún mecanismo se pone a la disposición del Delegado del Gobierno para obligar a la entidad local a responder expresamente el requerimiento, pero no lo es menos que tal circunstancia carece de cualquier trascendencia, pues el Delegado del Gobierno podrá en cualquier momento -al estar vencido ya el plazo en su momento concedido- considerar no atendido dicho requerimiento y proceder a la suspensión del acto local y a la adopción de las restantes medidas pertinentes, para -a continuación y en plazo legal- deducir el oportuno recurso contencioso-administrativo.

\subsubsection{La fase judicial del conflicto}

Esta fase no suscita problemas relevantes. En la medida en que el precepto legal habla sin más de la impugnación del acto o acuerdo ante la Jurisdicción Contencioso-Administrativa, ninguna duda ofrece que se está refiriendo al recurso contencioso-administrativo ordinario.

Ese recurso tiene por objeto, sin embargo, exclusivamente el acto o acuerdo local que dio lugar al requerimiento en vía gubernativa, así como -en su caso- la decisión ulterior del Presidente de la entidad local de no atender éste (decisión, cuyo contenido se limita, así, a declarar que no se aprecia que dicho acto o acuerdo atente gravemente al interés general de España). Siendo así, por tanto, que su objeto es un acto suspendido por una decisión del Delegado del Gobierno, que - por su parte- queda fuera de dicho objeto, parece claro que en el recurso no será posible plantear incidente alguno en orden a la adopción de medida cautelar o provisional alguna y, concretamente, la de suspensión gubernativa. Esta es la única, aunque no despreciable, peculiaridad que de la regulación legal examinada resulta para el procedimiento del recurso contencioso-administrativo.

Madrid, 18 de octubre de 1988. 